\title{
COMMODITY MARKET DYNAMICS AND THE JOINT EXECUTIVE COMMITTEE, 1880-1886
}

\author{
Franco Mariuzzo and Patrick Paul Walsh*
}

\begin{abstract}
Using weekly spot and future commodity prices in Chicago and New York, we construct expected transportation rates for grain between these two cities, expected inventory levels in New York, and realized errors in the expectations of such variables. We incorporate these exogenous commodity market dynamics into Porter's (1983) structural modeling of the Joint Executive Committee Railroad Cartel. As in Porter, we model marginal cost as a parametric function of (instrumented) output, among other factors. Unlike Porter, we model pricing over marginal cost as a nonparametric function of a set of variables, which include expectations of deterministic demand cycles and cartel stability. We estimate the pricing and demand equation simultaneously and semiparametrically. Our estimated weekly markups during periods of cartel stability are shown to reflect optimal collusive pricing over deterministic business cycles, as modeled in Haltiwanger and Harrington (1991). Periods of cartel instability are proven to be triggered by realized mistakes in expectations of New York grain prices.
\end{abstract}

\section{Introduction}

$\mathrm{T}$ HE Joint Executive Committee (JEC) Railroad Cartel acted as a legal cartel that transported grain between Chicago and New York during the period 1880 to $1886 .{ }^{1}$ A key issue for this paper, and for most of the literature on cartels, is to understand how a cartel sustains itself over deterministic demand cycles and in the presence of unexpected demand shocks, among other factors. Our innovation is to construct demand cycles and shocks from weekly data on spot and future grain prices on the Chicago and New York stock markets. Optimal inventory management of grain in New York during the nineteenth century, as written down by Coleman (2009), allows us to employ commodity prices to construct the expected rate for grain conveyance between Chicago and New York. Inventory management over the opening and closing of the Great Lakes is shown to generate anticipated expected deterministic cycles for transportation modalities in terms of expected transportation rates. We also employ spot and future commodity prices in New York to

Received for publication June 17, 2009. Revision accepted for publication June 7, 2012.

* Mariuzzo: University of East Anglia; Walsh: University College Dublin.

Andrew Coleman kindly gave us the weekly transportation price data that he collated from the Aldrich (1893) Senate report and the weekly commodity price data that he collated from the New York Times. This includes transportation rates on Great Lakes and canals, as well as commodity spot and future prices in the Chicago and New York Stock Market Exchanges from 1878 to 1886 . These data allow us to model the impact of commodity markets cycles and shocks on the price and quantity movements in the Joint Executive Committee Railroad Cartel. This paper was presented at the IOS conference in Boston 2006, and 2009, CEPR/IIIS productivity workshop in Dublin 2006, and EARIE 2006 in Amsterdam. We thank Silvi Berger, Robert Clark, Gregory Crawford, Peter Davis, John Haltiwanger, Joseph Harrington, Mike Harrison, Julie Mortimer, Ariel Pakes, Robert Porter, Paul Scott, John Sutton, Chad Syverson, and Ciara Whelan for helpful comments. We are extremely grateful to referees for helpful suggestions that have greatly improved our paper.

A supplemental appendix is available online at http://www.mitpress journals.org/doi/suppl/10.1162/REST_a_00320.

${ }^{1}$ The JEC was in operation before the establishment of the Interstate Commerce Commission in 1887 and the passing of the Sherman Act in 1890 . model scheduled inventory levels. Finally, we quantify realized errors in the expectations of transportation rates and inventory levels, created by unexpected shocks to the grain market in New York. We incorporate such previously omitted data into Porter's (1983) analysis of equilibrium pricing to generate estimates of weekly price-cost margin (degree of oligopoly power) dynamics that were not previously estimated and documented for this cartel. The pricing equation that Porter estimates is a generalized first-order condition for the $\log$ of pricing $\left(\ln G R_{t}\right)$ in an imperfectly competitive homogeneous goods market:

$$
\ln G R_{t}=-\ln \left(1+\frac{\theta_{t}}{\eta}\right)+\ln M C_{t} .
$$

Our empirical strategy is to estimate this equation with random errors. We work with precisely the same functional form for cost employed by Porter. We impose a log-linear marginal cost function $\left(\ln M C_{t}\right)$ that, among other factors, depends on the log of output (demand). Thus, a model of demand will be simultaneously estimated with pricing. Our first innovation is to enrich the modeling of demand, and hence marginal cost, by expanding its primitives. We then compute the JEC overall elasticity of demand, $\eta$, to be made up of the own- and crossprice elasticity, as theoretically outlined in Holmes (1989). Thus, demand will be specified to depend on the expected rate of the outside transportation option, among other new controls.

Our second innovation is motivated by the work of Appelbaum (1982). We model Porter's "hidden regime" (omitted variables), the $\log$ transformation of the markup, $-\ln \left(1+\frac{\theta_{t}}{\eta}\right)$, as a nonparametric function of a set of variables that reflect expectations of demand cycles and cartel stability. ${ }^{2}$ We wish to show how the inclusion of previously omitted data on expected demand cycles and demand shocks into this nonparametric function will allow us to estimate rich price-cost margin dynamics for this cartel. ${ }^{3}$ We include the following observables in a nonparametric modeling of what was Porter's unobservable markup: the expected rate of the outside transportation option (which has a one-period-forward

\footnotetext{
${ }^{2}$ Theory based on repeated games suggests that Bresnahan's (1989) $\theta$ is not static, as the intensity of price competition (market share rivalry) can vary over time. The way one models demand affects the trade-off between one-shot gains and discounted losses in incentive compatibility constraints in repeated games. This has been shown to generate very different time paths of the conduct and equilibrium price-cost margin (see, for example, Green \& Porter, 1984; Rotemberg \& Saloner, 1986; Haltiwanger \& Harrington, 1991; Fabra, 2006). Genesove and Mullin (1998) provides us with a "sweet" overview of the empirical issues surrounding the estimation of the generalized first-order condition for pricing in homogeneous good industries.

${ }^{3}$ We provide a direct comparison of our results with Porter and for this reason make no attempt to separate out this function in pricing from costs using the techniques suggested in Berry, Levinsohn, and Pakes (1995), overviewed in Mariuzzo, Walsh, and Whelan (2010).
} 
expectation on the future of the New York commodity price); a control for additional demand cycles created by inventory management in New York (we expect increasing pressures to build up inventories as the number of weeks that the Great Lakes are open decrease or, if in Lakes Great closed periods, New York can bargain credibly with railroads to lower prices, as the number of weeks to Great Lakes opening decrease); finally, we include a probability of cartel stability in the next period, in the markup term.

Instability in this cartel is defined, as documented by Porter, as a finite period of revision to low markups to sustain the cartel; this is modeled in Green and Porter (1984). We find that Porter's estimates of such finite revision phases are very similar to the periods of cartel instability, defined in the Aldrich Report (1893) (our new data source). Following Ellison (1994) we face off anticipated demand cycles against unanticipated demand shocks (realized mistakes from a historical expectation of a New York future) as triggers of finite periods of instability, all else equal. Consistent with Ellison, we find that realized errors in past expectations, created by unexpected commodity price shocks in New York, are the reason for the JEC's lapsing into finite periods of instability. ${ }^{4}$

Incorporating data on deterministic cycles and unexpected demand shocks into our econometric modeling of a generalized first-order condition for pricing, in an imperfectly competitive homogeneous good market, gives us a richer model of the factors driving JEC pricing over marginal cost. This is done using an innovative semiparametric approach for estimating pricing simultaneously with demand. While the results are broadly consistent with Ellison in terms of our analysis of stability and demand, we do find that the anticipated cyclical nature of demand is important for markups (pricing). We show that the JEC was able to manage optimal collusive pricing over deterministic cycles as modeled in Haltiwanger and Harrington (1991), also reiterating the findings in Borenstein and Shepard (1996). In section II, we describe the data and literature. In section III, we replicate Porter and introduce our extension. In section IV, we provide results. Finally, we draw some conclusions in section V.

\footnotetext{
${ }^{4}$ Several theoretical papers have discussed this problem within the JEC from both traditional and game-theoretic frameworks. The focus of this work has been on the causes of so-called price wars, or periods of instability, identified by Porter (1983). The key papers on this issue are Ulen (1983), Porter (1985), Ellison (1994), Rotemberg and Saloner (1986), and Vasconcelos (2004). The core aim of the Ellison paper is to try to understand plausible trigger strategies that could send the cartel into finite periods of punishment. His main finding is that unexpected demand shocks in the AR(1) residual of demand triggered the price war. This is tested against a Rotemberg and Saloner (1986) effect, where the incentive compatibility constraint (ICC) comes under pressure when anticipated demand is high in the current period but low in the next period. Using data on commodity markets in New York, we intend to show that unanticipated commodity market shocks in New York were the trigger and not the cyclical nature of pricing as controlled by us. This is compatible with the findings of Ellison. As in Ellison, unusual movements in the market shares of companies are not found to be the culprit. It seems that a common external unanticipated commodity shock was the trigger, consistent with the mechanisms in the trigger strategy discussed in Green and Porter (1984).
}

\section{The Literature and Data Sources}

The JEC railroad cartel managed eastbound freight shipments of grain, flour, and provisions from Chicago to the Atlantic Coast. Grain was by far the most important commodity that the cartel transported. The JEC was a legal cartel that set official rates and market share allotments for companies with traffic out of Chicago. In this section, we undertake a detailed analysis of the data summarized in table 1 . Some of the data have already been used in the literature on this famous cartel. We provide a summary of these analyses. In the second part of table 1, we introduce our new variables. One set of new variables comes from the Aldrich Report (1893), which details transportation rates for all transportation modalities, including steamships, between Chicago and New York. The report also documents detailed information on the opening and closing of Great Lakes and canals, and finally, reports when the JEC did not peg to a recommended railroad rate that all railroads, including the JEC, were supposed to adhere to, in the transportation of grain between Chicago and New York. We also construct a new set of variables, described and motivated below, from weekly data on grain commodity prices from the New York Times.

\section{A. Porter Data}

Statistics on the functioning of the JEC cartel were published in weekly reports in the Railway Review and the Chicago Tribune. Ulen (1979) has collated this information into weekly time series data. Porter (1983) employed this data set to provide empirical evidence of revisions in this cartel to finite periods of low markups. We reproduce summary statistics for the variables that Porter used in the first part of table 1 . The period of reference spans from January 1, 1880, to April 18, 1886, a total of 328 weeks. The key endogenous variables for Porter, and for us, are the weekly official JEC grain transportation rate, $G R$, and the weekly tons of grain shipped, $Q$. Porter uses a Great Lakes dummy, $L$, that controls for when the lakes were open and closed. The Aldrich Report (1893) gives us more detailed data on the timing of the opening and the closing of the ports of the lakes and the canals. In addition to the dummies representing the line expansion of companies (S1-S2), and the entry (S3) and exit (S4) of companies, Porter also reports data on periods of cartel stability, measured by the binary variable $P O$. $P O$ is the variable that Ulen (1979) constructed on the basis of internal reports of adherence within the cartel. The main focus of the Porter's (1983) paper was to estimate a $P N$ binary variable endogenously in a hidden switching regime model that reflected finite switches to periods of low markups in the JEC cartel. The Aldrich Report (1893) gives us new data to construct a dummy, $P R$, on the JEC's periods of instability. We come back to a description of the Aldrich data below.

\section{B. Ellison Data}

Ellison (1994) extends the Porter analysis by imposing a Markov structure on the transitions to finite periods of 
TABLE 1.-Summary STATISTICS

\begin{tabular}{|c|c|c|c|c|c|c|}
\hline Variable name & Definition & Observations & Mean & SD & Minimum & Maximum \\
\hline \multicolumn{7}{|c|}{ A. Porter } \\
\hline GR & The official grain rate, in dollars per 100 pounds. & 328 & 0.246 & 0.067 & 0.125 & 0.400 \\
\hline $\mathrm{L}$ & $\begin{array}{l}\text { Great Lakes dummy, reported as } 1 \text { when lakes are } \\
\text { open, } 0 \text { otherwise. }\end{array}$ & 328 & 0.573 & 0.495 & 0 & 1 \\
\hline $\mathrm{PO}$ & $\begin{array}{l}\text { Cheating dummy as reported in the Railway Review } \\
\text { and Chicago Tribune. }\end{array}$ & 328 & 0.619 & 0.486 & 0 & 1 \\
\hline PN & Estimated cheating dummy. & 328 & 0.750 & 0.434 & 0 & 1 \\
\hline $\mathrm{Q}$ & Total quantity of grain shipped in tons. & 328 & 25,384 & 11,632 & 4,810 & 76,407 \\
\hline$S_{1}$ & $\begin{array}{l}\text { Dummy equal to } 1 \text { from week } 28 \text { in } 1880 \text { to week } 10 \\
\text { in } 1883,0 \text { otherwise. This period reflects the } \\
\text { opening of a new line by Grand Trunk Railway. }\end{array}$ & 328 & 0.424 & 0.495 & 0 & 1 \\
\hline$S_{2}$ & $\begin{array}{l}\text { Dummy equal to } 1 \text { from week } 11 \text { in } 1883 \text { to week } 25 \\
\text { in } 1883,0 \text { otherwise. This period reflects the } \\
\text { opening of a new line by New York Central. }\end{array}$ & 328 & 0.046 & 0.209 & 0 & 1 \\
\hline$S_{3}$ & $\begin{array}{l}\text { Dummy equal to } 1 \text { from week } 26 \text { in } 1883 \text { to week } 11 \\
\text { in } 1886,0 \text { otherwise. This period reflects the entry } \\
\text { of Chicago and Atlantic Railways. }\end{array}$ & 328 & 0.433 & 0.496 & 0 & 1 \\
\hline$S_{4}$ & $\begin{array}{l}\text { Dummy equal to } 1 \text { from week } 12 \text { in } 1886 \text { to week } 16 \\
\text { in } 1886,0 \text { otherwise. This period reflects the } \\
\text { departure of Chicago and Atlantic Railways. }\end{array}$ & 328 & 0.015 & 0.123 & 0 & 1 \\
\hline \multicolumn{7}{|c|}{ B. Ellison ${ }^{\mathrm{a}}$} \\
\hline $\mathrm{N}$ & Number of firms (railroads). & 328 & 4.351 & 0.627 & 3 & 5 \\
\hline BIG1 & $\begin{array}{l}\text { Unusually high market share of one firm } \\
\text { (measure 1). }\end{array}$ & 327 & $\begin{array}{c}1.072 \\
{[1.091]}\end{array}$ & $\begin{array}{c}0.548 \\
{[0.569]}\end{array}$ & $\begin{array}{c}0.130 \\
{[0.040]}\end{array}$ & $\begin{array}{l}3.156 \\
{[2.971]}\end{array}$ \\
\hline BIG2 & $\begin{array}{l}\text { Unusually high market share of one firm } \\
\text { (measure 2). }\end{array}$ & 327 & $\begin{array}{l}1.141 \\
{[1.241]}\end{array}$ & $\begin{array}{c}0.680 \\
{[0.710]}\end{array}$ & $\begin{array}{c}0.169 \\
{[0.185]}\end{array}$ & $\begin{array}{l}3.975 \\
{[4.235]}\end{array}$ \\
\hline BIGQ & $\begin{array}{l}\text { Unusually high market share of one firm } \\
\text { (measure 3). }\end{array}$ & 327 & $\begin{array}{l}1.971 \\
{[1.174]}\end{array}$ & $\begin{array}{c}0.945 \\
{[0.516]}\end{array}$ & $\begin{array}{c}-0.148 \\
{[0.158]}\end{array}$ & $\begin{array}{c}4.888 \\
{[2.973]}\end{array}$ \\
\hline SMALL1 & $\begin{array}{l}\text { Unusually small market share of one firm } \\
\text { (measure 4). }\end{array}$ & 327 & $\begin{array}{l}1.139 \\
{[1.230]}\end{array}$ & $\begin{array}{c}0.700 \\
{[0.737]}\end{array}$ & $\begin{array}{l}0 \\
{[0.116]}\end{array}$ & $\begin{array}{c}6.116 \\
{[5.757]}\end{array}$ \\
\hline \multicolumn{7}{|c|}{$\begin{array}{l}\text { Our New Variables } \\
\text { C. Aldrich Report }\end{array}$} \\
\hline GRAll & $\begin{array}{l}\text { Grain rate of transport by all railroads in dollars per } \\
100 \text { pounds. Available for the period } 1878-1891 \text {. }\end{array}$ & 328 & 0.254 & 0.059 & 0.140 & 0.400 \\
\hline GRLC & $\begin{array}{l}\text { Grain rate of transport by Great Lakes and canals in } \\
\text { dollars per } 100 \text { pounds. Available for the period } \\
1878-1883 \text {. }\end{array}$ & 138 & 0.153 & 0.046 & 0.063 & 0.288 \\
\hline GRLR & $\begin{array}{l}\text { Grain rate of transport by Great Lakes and railroads } \\
\text { in dollars per } 100 \text { pounds. Available for the period } \\
1878-1891 .\end{array}$ & 190 & 0.185 & 0.044 & 0.110 & 0.295 \\
\hline $\mathrm{LC}$ & $\begin{array}{l}\text { Lakes and canals dummy, reported } 1 \text { when } \\
\quad G R L C>0,0 \text { otherwise. }\end{array}$ & 138 & 0.421 & 0.494 & 0 & 1 \\
\hline LR & $\begin{array}{l}\text { Lakes and railroads dummy, reported } 1 \text { when } \\
\quad G R L R>0,0 \text { otherwise. }\end{array}$ & 190 & 0.579 & 0.494 & 0 & 1 \\
\hline PR & $\begin{array}{l}\text { A dummy equal to } 1 \text { if the JEC grain rate was equal } \\
\text { to the Chicago-New York grain rate that railroads, } \\
\text { including the JEC, tried to peg to; } 0 \text { otherwise. }\end{array}$ & 328 & 0.765 & 0.424 & 0 & 1 \\
\hline$P R N$ & Estimated PR dummy (see section IIIB). & 328 & 0.759 & 0.428 & 0 & 1 \\
\hline \multicolumn{7}{|c|}{ D. New York Times } \\
\hline$G P^{N Y}$ & New York spot (call) corn prices. ${ }^{\mathrm{b}}$ & 328 & $\begin{array}{l}.009 \\
1.105\end{array}$ & $\begin{array}{l}0.209 \\
0.187\end{array}$ & $\begin{array}{l}0.603 \\
0.817\end{array}$ & $\begin{array}{l}1.482 \\
1.946\end{array}$ \\
\hline$G P 1^{N Y, E}$ & $\begin{array}{l}\text { New York future corn prices for delivery within the } \\
\text { month. }\end{array}$ & 320 & 1.097 & 0.186 & 0.815 & 1.964 \\
\hline $\mathrm{GR}^{* E}$ & $\begin{array}{l}\text { Proxy for transportation rates of competitors }= \\
\qquad\left(G P 1^{N Y, E}-G P^{C H}\right) .\end{array}$ & 320 & 0.208 & 0.085 & 0.010 & 0.750 \\
\hline ER & Error in expectations $=\left(G P 1^{N Y, E}-G P^{N Y}\right)$. & 320 & -0.008 & 0.058 & -0.393 & 0.554 \\
\hline $\mathrm{MNCY}^{E}$ & $\begin{array}{l}\text { Proxy for marginal net convenience yield }= \\
\qquad\left(G P^{N Y}-G P 1^{N Y, E}\right) .\end{array}$ & 320 & 0.010 & 0.020 & -0.045 & 0.123 \\
\hline \multicolumn{7}{|l|}{ Other } \\
\hline NWC & $\begin{array}{l}\text { Yearly de cumulative number of weeks to the } \\
\text { opening of Great Lakes ( } 0 \text { when open). }\end{array}$ & 328 & 4.159 & 6.282 & 0 & 23 \\
\hline NWO & $\begin{array}{l}\text { Yearly cumulative number of weeks the lakes remain } \\
\text { open ( } 0 \text { when closed). }\end{array}$ & 328 & 9.311 & 10.636 & 0 & 34 \\
\hline$\tilde{Q}$ & $\begin{array}{l}\text { Estimated output business cycle (estimated using } \\
\text { Hodrick and Prescott's (1997) filter). }\end{array}$ & 328 & 25,384 & 6,973 & 10,517 & 41,485 \\
\hline
\end{tabular}

${ }^{a}$ In square brackets the values computed by Ellison. Because of a different way of averaging over the first twelve weeks, our reproduction of Ellison's variables is slightly different from the original. The first of Ellison's variables, BIG1 $t_{t}$, is aimed at capturing a particularly high market share for one of the firms in the cartel, and its value is computed as max $\frac{\left(s_{i t}-\bar{S}_{i}\right)}{\sigma_{i}}$. With the market share of firm $i$ in period $t$ defined as $s_{i t} \equiv\left(\ln Q_{i t}-\frac{1}{N_{t}} \sum_{j} \ln Q_{j t}\right)$, and the term $\bar{s}_{i t}$ denoting the average market share of firm $i$ over the previous twelve weeks (for the first twelve weeks the average is over any previous available week). The heteroskedastic parameter $\sigma_{i}$ indicates firm-specific standard deviations. $N_{t}$ labels the number of firms in the cartel in period $t$. BIG $2_{t}$ is a variant of BIG1 $1_{t}$, with the only difference being that the market share is defined with $s_{i t} \equiv \frac{Q_{i t}}{Q_{t}}$. $\mathrm{BIGQ}_{t}$ is another variant of BIG1 $1_{t}$, which uses $s_{i t}$ as defined in $\mathrm{BIG}_{t}$, but computes the average $\bar{s}_{i t}$ over the allotted market shares $a_{i t}$. The last of Ellison's variables is SMALL1 $1_{t}$. Its role is to detect an unusually small market share for one of the firms in the cartel. It is calculated each period $t$ as the $\min \left\{\min _{i} \frac{\left(s_{i t}-\bar{s}_{i t}\right)}{\sigma_{i}}, 0\right\}$, where $s_{i t}$ and $\bar{s}_{i t}$ are those earlier defined for BIG1 $1_{t}$. In our data, two observations have min $\frac{\left(s_{i t}-\bar{s}_{i_{i}}\right)}{\sigma_{i}}>0$, and thus have SMALL1, equal to 0

${ }^{b}$ Weekly average of daily prices, where a daily price is the average between the minimum and maximum price of the day. 
unobservable price wars. He estimates the coefficients of the demand and the pricing model of Porter by maximizing the joint likelihood of a system of demand, pricing, and paths of transitions into and out of cartel instability. He imposes an autoregressive structure for the residuals of the Porter demand function and finds evidence of hidden regimes in demand (omitted variables). The core aim of Ellison's paper was to try to understand plausible trigger strategies that could send the cartel into finite periods of punishment. He tested, but found little evidence of, four triggers constructed from disaggregated railroad-level data, each designated to proxy for signals of cheating by firms inside the cartel. Computing these internal firm-level variables requires having railroad-level data on assigned quotas and actual market shares. We replicate his variables for use in our empirical equation of cartel stability. We document our reproduction in table 1 and detail the construction of each of these variables in a footnote to the table. Overall, Ellison found evidence that random demand-side shocks triggered transitions to cartel instability. This will be shown to be consistent with our results, but we model these as actual shocks in the New York commodity market. Unlike us, he finds no evidence that cyclical or seasonal demand cycles had any impact on the general run of pricing.

\section{Aldrich Data}

The Aldrich Report (1893) provides data on weekly transportation rates for shipments of grain between Chicago and New York over the Great Lakes and canals (GRLC), over Lakes and Railroads (GRLR), and the rate recommended for all railroads (GRAll). Summary statistics are provided in table 1. To understand the nature of these prices, we need to summarize the historical context.

To facilitate the movement of grain from the Great Plains to Europe after harvesting, there was a rush to get the commodity over the GRLC before they closed, to New York for storage in grain elevators (huge warehouses). The slowest and least expensive method was to transport to Buffalo by ship via the Great Lakes and then on to New York along the Erie Canal (purposely enlarged during in 1836 and 1862). This took approximately three weeks. A faster and more expensive method, taking ten days, was to ship it to Buffalo and then transport it by rail to New York. This was useful particularly as the canals would freeze up before the ports of the lakes. Transportation over the Great Lakes was not available between November and late April, as both the canals and the ports of the lakes were frozen. The fastest and most expensive method, available all year, was to send grain over three days by rail to New York.

Having the rates for shipments on different modalities in the Aldrich Report (1893), we can recover more detailed information on the timing of lake opening and closing, relevant for the lake reliant methods of shipping: the lakes and canals (LC) or the lakes and railroads (LR). Table 2 documents yearly information on the number of weeks that Porter's-Lakes, LC, and LR remain open. Canals freeze
TABLE 2.-Number of WeEKS LAKes OPen (L, FROM PORTER), LAKES AND RAILROADS OPEN (LR, FROM ALDRICH), LAKES AND CANALS OPEN (LC, FROM ALDRICH), AND NUMBER OF WEEKS OF STABILITY BASED ON PO (FROM PORTER), PR (FROM ALDRICH), AND THEIR ESTIMATES

\begin{tabular}{rrrrrrrrr}
\hline \hline Year & Number of Weeks & L & LR & LC & PO & PN & PR & PRN \\
\hline 1880 & 52 & 34 & 33 & 33 & 52 & 52 & 51 & 52 \\
1881 & 52 & 28 & 29 & 26 & 15 & 26 & 26 & 26 \\
1882 & 52 & 33 & 35 & 32 & 48 & 41 & 40 & 41 \\
1883 & 52 & 33 & 31 & 27 & 47 & 52 & 49 & 52 \\
1884 & 52 & 31 & 32 & $a$ & 22 & 33 & 26 & 33 \\
1885 & 52 & 29 & 30 & $a$ & 12 & 26 & 24 & 29 \\
1886 & 16 & 0 & 0 & $a$ & 7 & 16 & 15 & 16 \\
Total & 328 & 188 & 190 & 118 & 203 & 246 & 251 & 249 \\
\hline
\end{tabular}

${ }^{a}$ Not available for the period $1884-1886$.

before the ports of the Great Lakes, and hence we see longer periods of lakes open in the case of LR. Yet the duration of Great Lakes open using $L, L C$, and $L R$ dummies is very similar, and for that reason, in our empirical analysis we stay loyal to Porter and employ his Lakes dummy, $L$.

The Aldrich Report (1893) also gives us new data on periods of nonadherence of the JEC to recommend transportation rates set for grain across all railroads. We use this to construct a dummy, $P R$, on the JEC's periods of instability, as we detail in section IIIB, where $P O$ (as previously defined) and $P R$ are used as starting values to endogenously estimate the hidden switching regimes $P N$ and $P R N$. A brief overview of the behavior of these four variables is given in tables 1 and 2 . From table 1, it emerges that $P O$ and $P R$ are different, as the number of periods of stability in cartel pricing in the JEC are greater using the $P R$ dummy. Stability is broken down year by year in table 2 . The presence and variation of instability is different when we compare $P O$ and $P R$. Interestingly, we see that $P R$ is comparable to the $P N$ cheating binary variable estimated endogenously by Porter, and $P R N$ has little added value. Our use of $P R$ as data that do not need to be estimated proves to be important in our empirical methodology, and we justify our position on this further in our empirical section.

\section{New York Times Commodity Data}

Our core ambition in this paper is to reexamine the functioning of the JEC cartel with commodity market data that control for deterministic pricing cycles between Chicago and New York, expected inventory levels in New York, and unexpected errors in expectations in these variables. Table 1 offers definitions and summary statistics for the Chicago and New York (spot and future) commodity prices and the three variables that we construct from commodity prices.

We turn first to the construction of a variable from commodity prices that will control for expected pricing cycles. In terms of transporting grain from Chicago to New York, elevators tried to stock inventories supplied by the cheap and slow, but closed during the winter, mode of transportation. During the period 1878 to 1890, Coleman (2009) estimates that 95\% of corn was transported in the open water season and was shipped by the Great Lakes. This created interesting demand cycles for the JEC to price against. Coleman writes down a 
Figure 1.-Modes of transportation Rates: Lakes and CANals (GRLC, Dashed Line), JEC Railroads (GR, Plus Sign), Expected Outside Transportation Option (GR ${ }^{* E}$, Line), Lakes Open Period $(L=1$, Diamond at .5), Cartel Instability Period $(P R=0$, Triangle at 0$)$

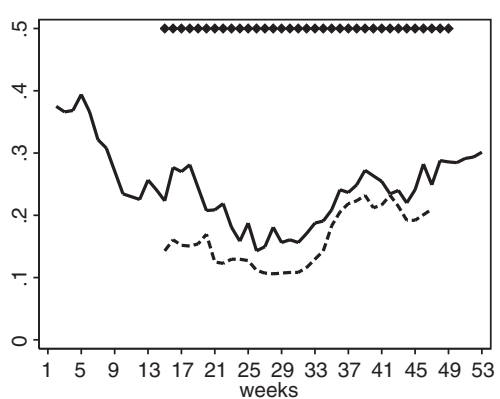

(a) Year 1878

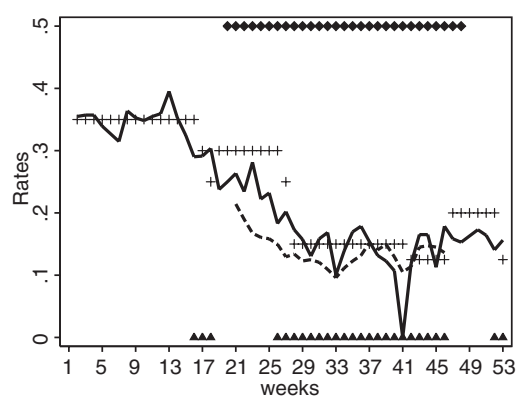

(d) Year 1881

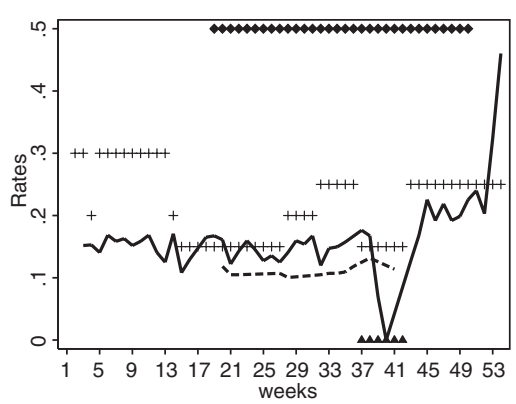

(g) Year 1884

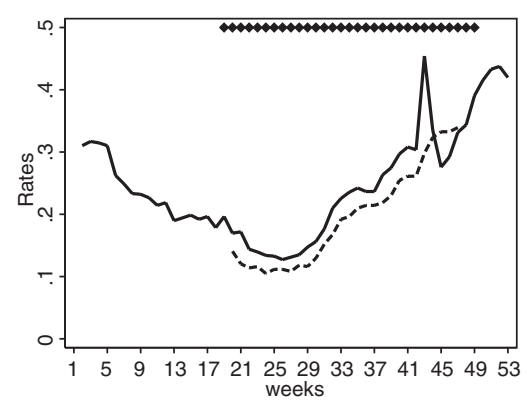

(b) Year 1879

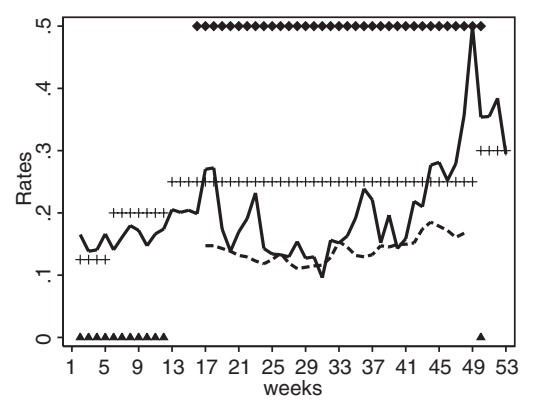

(e) Year 1882

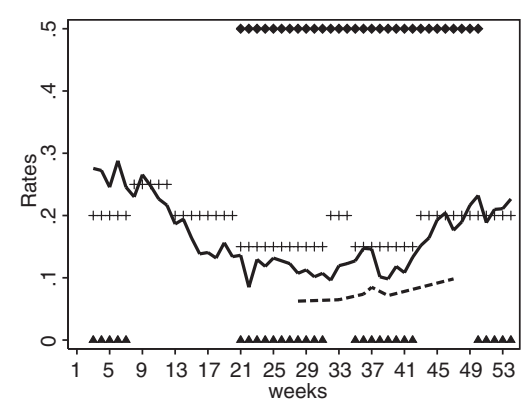

(h) Year 1885

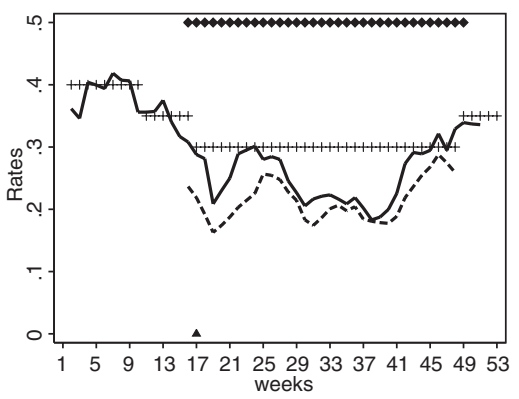

(c) Year 1880

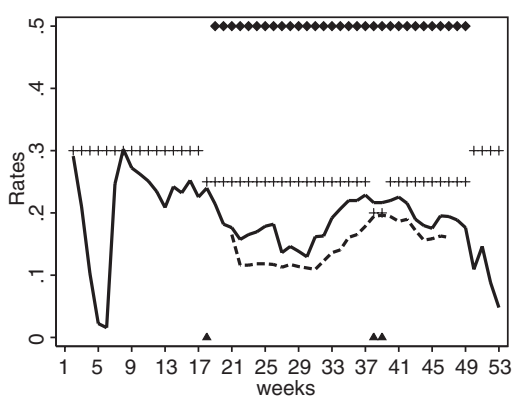

(f) Year 1883

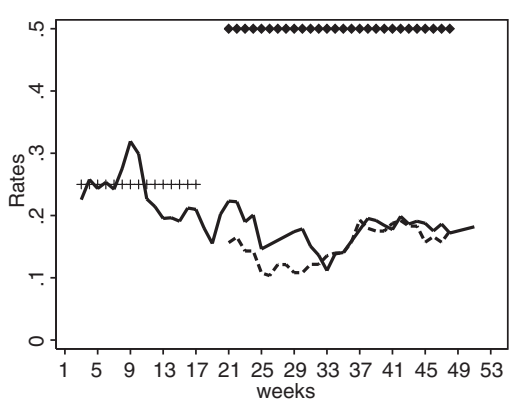

(i) Year 1886 model and provides empirical evidence that the weekly discrepancy between the spot commodity price in Chicago and the future commodity price in New York is a good measure of the expected transportation and storage costs of moving grain from Chicago to New York. We use this variable in both our demand and pricing equations. While it is common to include the price of a competing product in the demand side, we also include it in the pricing equation and model the JEC as a Stackelberg price follower. Outside transportation options over the GRLC were by far the major players in the shipment of grain from Chicago to New York. The railroads that made the JEC cartel were small players and hence were followers in a global pricing system. We define the expected outside option in transportation rates facing the JEC as ${ }^{5}$

$$
G R_{t}^{* E} \equiv E_{t}\left(G P_{t+1}^{N Y}\right)-G P_{t}^{C H},
$$

${ }^{5}$ Our proxy is also valid when the Great Lakes are frozen, since competition from non-JEC railroad companies was present, as was competition from inventories from the Great Lakes in New York. where $G P^{C H}$ and $G P^{N Y}$ are the commodity prices of grain set in the Chicago and New York stock markets. The speed of the delivery by the JEC cartel ensured that if any weekly top-ups were necessary in New York to meet demand, the railroad cartel would oblige. The +1 in the expectation of equation (2) postulates that it takes one period to ship the grain via the Great Lakes from Chicago to New York.

The expected weekly transportation rate between Chicago and New York $G R^{* E}$ has interesting dynamics all year. Using data in the Aldrich Report (1893), one can find the actual rates for competing modes of transportation that used the LC or LR options. This allows us to compare and validate our expected outside option variable constructed from commodity prices. Figure 1 relates the pattern of weekly shipment rates between Chicago and New York in each year in terms of the JEC official rate (Porter's GR), the rate over the Great Lakes and canals $(G R L C)$, and the expected transportation rate $G R^{* E}$, as defined above. We notice that $G R^{* E}$ shares the same trends of the JEC rate, $G R$, and the rate for shipments over the Great 


\begin{tabular}{|c|c|c|c|c|}
\hline & GR & GRLC & GRLR & $\mathrm{GR}^{*}$ \\
\hline GR & $1.00(328)$ & & & \\
\hline GRLC & $0.65^{\dagger}(138)$ & $1.00(138)$ & & \\
\hline GRLR & $0.79^{\dagger}(190)$ & $0.86^{* *}(137)$ & $1.00(190)$ & \\
\hline $\mathrm{GR}^{* E}$ & $0.65^{\dagger}(320)$ & $0.81^{* *}(135)$ & $0.62^{* * *}(187)$ & $1.00(320)$ \\
\hline
\end{tabular}

In bracket number of observations. Significant at $95 \%$ confidence level.

Lakes and canals, GRLC. ${ }^{6}$ Table 3 shows a strong positive correlation between $G R^{* E}$ and the rates of alternative modes of conveyance. In Figure 1 we also plot LC transportation rates and our expected transportation rate in the years before the JEC (1878-1879) in figures $1 \mathrm{a}$ and $1 \mathrm{~b}$ and in the years of the JEC (1880-1886) in figures 1c to 1i. The most striking feature of transportation rates occurs in the Great Lakes open period. During Lakes open, the rates decrease up to harvesting, then increase as we move toward the closing of the lakes. This effect is created by elevators in New York building up stocks for the winter. We also observe that during Great Lakes closed, the rates increase and then decrease. Such downward trends on railroad rates in the weeks before lakes opening seem to reflect declining railroad bargaining power as the time to lakes opening shortens. These cyclical movements in the expected transportation rates before and after the formation of the JEC suggest to us that the opening and closing of the Great Lakes had effects on demand and pricing (via the internal incentive compatibility constraint, ICC) in the weeks running up to their closing and opening. This should be captured by our expected weekly transportation rate between Chicago and New York $G R^{* E}$ variable, which will control for anticipated pricing cycles, pressures outside the control of the JEC, at least one period ahead.

The presence of deterministic cycles created by harvesting and inventory management over the opening and closing of the Great Lakes leads us to control for anticipated demand cycles that look further into the future. We do this by creating two variables that reflect the cumulated number of weeks that the lakes remained open at a given point in time in a year, $N W O$, and the countdown on the number of weeks until they reopened at a given point of time in a year, $N W C$. NWO starts with a value of 1 associated with the first week the Great Lakes are accessible to navigation and reaches its maximum the week prior to the their freezing again. The variable is set to 0 during the period in which the lakes are closed for navigation. $N W C$ has its maximum the first week the lakes are not accessible to navigation and reduces to a value of 1 the week before the lakes reopen to navigation. The variable is set to 0 during lakes open. Therefore, rather than having a simple lakes open and closed dummy, we have varying degrees of pressures coming from the expectations of lakes opening and closing represented by $N W C$ and $N W O$, which together exhibit an asymmetric sawtooth profile. The latter reflects the

\footnotetext{
${ }^{6}$ In order to make the figure more readable, we have purposely omitted the lakes and railroads rate (GRLR). Its yearly trends are comparable to those of the variable GRLC but with slightly greater values.
}

Figure 2.-Demand ( $Q$, Dashed Line), Estimated Demand Business Cycles ( $\tilde{Q}$, Bold Dashed Line), Lakes Open Period $(L=1$, Diamond at $80000)$, Cartel Instability Period $(P R=0$, Triangle at 0$)$

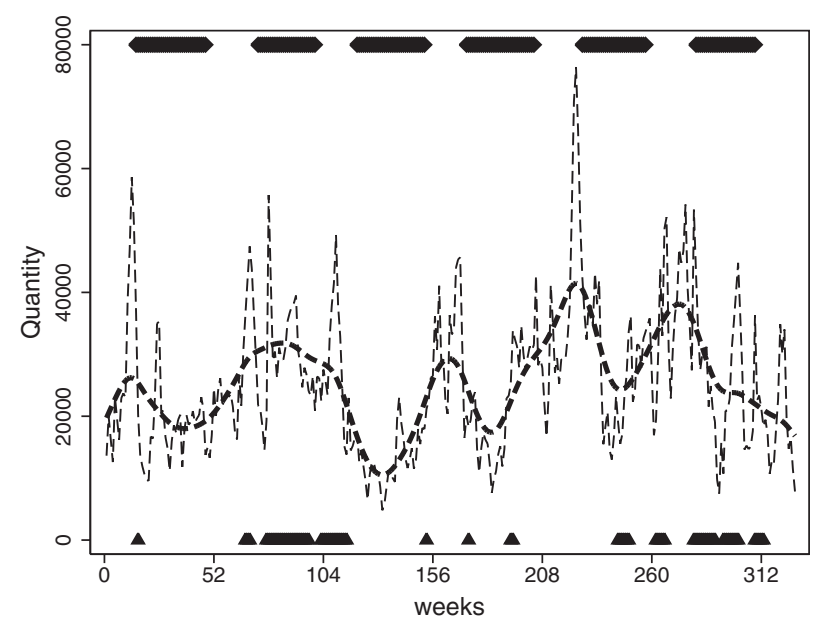

pressure to transport grain to inventories in New York after the harvest to avoid exposure to high transportation rates during the winter. The former embodies grain elevators' increased ability to bargain with the JEC as the weeks to lakes opening come nearer. We can see some evidence of these forces at work by plotting in figure 2 smoothed cycle of the JEC shipments of grain with our lakes open and cartel stability dummies. ${ }^{7}$ Inventory management in New York made shipment cycles for the JEC over the lakes open and closed regime more complex. We have four periods of lakes open when the cartel is generally stable. Shipments fall at first in lakes open regimes but then rise after harvesting, up to and beyond lakes closing. Inventory management and the closing of the lakes create an interesting U-shaped demand cycle for the cartel. ${ }^{8}$ Could controls for $N W C$ and $N W O$ reflect week effects in current demand rather than expectations of demand cycles? We do control for current output and the expected pricing from outside options, but we will verify, postregression, that for the same level of current demand, in either lakes open or closed, estimated markups are higher going into a period of growing demand and lower going into a slump. This will reflect the broader role of expected demand cycles created by the lakes opening and closing and, more important, optimal cartel pricing over such.

We now introduce a control for inventory levels constructed from commodity prices in New York. Elevators had the key role of storing the commodity. They solved intertemporal (dynamic) models and determined the optimal amount of grain to keep in stock. A by-product of their optimization was the demand for transportation. We relate the amount of grain available as inventory in elevators in period $t, Y_{t}$,

\footnotetext{
${ }^{7}$ We make use of Hodrick and Prescott's (1997) filter and estimate smoothed business cycles, which we denote with $\tilde{Q}$. We plot those against the actual demand in figure 2 .

${ }^{8}$ We count only six Great Lakes open spells during the cartel period because the cartel was declared illegal before the opening of the lakes in 1886.
} 
Figure 3.-Marginal Net Convenience YiEld Function

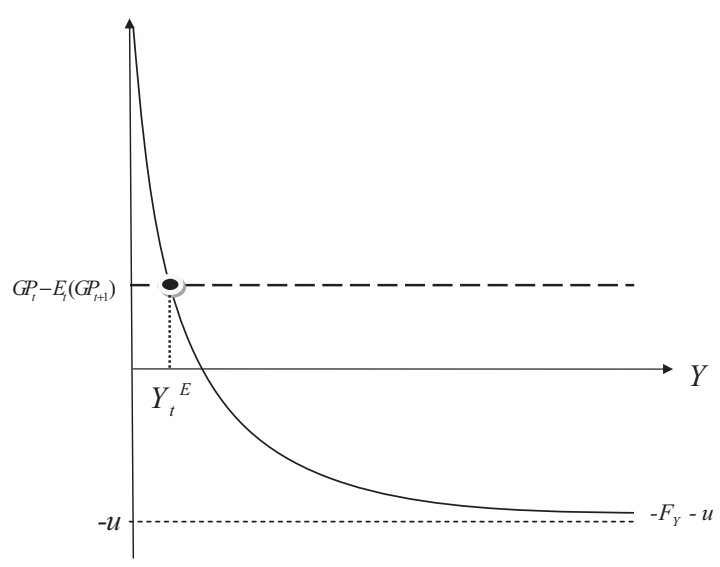

to the amount of grain imported (mainly from Chicago) in period $t, M_{t}$, to the contemporaneous consumption (mainly the amount of grain shipped to Europe), $C_{t}$ and to lagged inventory, as

$$
Y_{t}=Y_{t-1}+M_{t}-C_{t} .
$$

The volume imported is the result of transportation by ship or train. ${ }^{9}$ Similar to Thurman (1988) and Pindyck (1994), we formulate the cost of holding inventories as the sum of a unit cost for the physical use of grain elevators, $u$, and a function of current inventories, expected future consumption and current commodity prices, $F\left[Y_{t}, E_{t}\left(C_{t+T}\right), G P_{t}\right]$. We assume the function $F$ to be well behaved, strictly convex in $Y$, and increasing in $G P$ and in the expectation variable $C^{E}$. Under optimal inventory management, the negative of the marginal cost of inventories is the net benefit of an extra unit of inventory and is known in the literature as marginal net convenience yield. It is here defined as ${ }^{10}$

$$
\operatorname{MNCY}(Y ; u) \equiv-F_{Y}-u,
$$

where the partial derivative of $F$ with respect to the argument $Y$ is assumed negative, $F_{Y}<0$, and the cross-derivatives $F_{Y C}$ and $F_{Y H}$ are set to be 0 . We sketch the marginal net convenience yield function against the inventory level in figure 3 . The presence of future contracts with all arbitrage opportunities exploited is an optimal allocation of inventories across time, and we expect the following equality condition to hold:

$$
\operatorname{MNCY}\left(Y_{t}^{E}\right)=G P_{t}-\left(\frac{1-\delta}{1+r}\right)^{T} E_{t}\left(G P_{t+T}\right) .
$$

That is, the difference between a spot commodity price and the future commodity price $T$ periods ahead, discounted for

\footnotetext{
${ }^{9}$ Given that railroads can convey grain within three days, we assume that they are able to provide immediate delivery (within the week). In addition, we postulate that the alternative modes of transportation meet deliveries within the following period. In this way, $M_{t}$ casts the sum of transport by railroads (R) and by lakes (L), as follows: $M_{t} \equiv M_{t}^{R}+M_{t-1}^{L}$.

${ }^{10} \mathrm{~A}$ term originally introduced by Working (1949).
}

the depreciation commodity rate $(\delta)$ and the foregone longrun interest rate $(r)$, can be used to identify the expected equilibrium level of our second key variable: the marginal net convenience yield. Without loss of generality, in the rest of the paper, we use a simplified version of equation (5) that relies on setting $\delta=r=0$, so as to have

$$
\operatorname{MNCY}\left(Y_{t}^{E}\right) \equiv M N C Y_{t}^{E}=G P_{t}^{N Y}-E_{t}\left(G P_{t+1}^{N Y}\right) .
$$

Because of the presence of uncertainty in future commodity prices, equilibrium equation (6) backs out an expected optimal level of inventories that is negatively related to the marginal net convenience yield of the period in question as documented in figure 3. As demonstrated in Coleman (2009), New York (NY) was by far the main receiving city from Chicago $(\mathrm{CH})$. So we can use the difference between a spot and a future price in New York as a good measure of the (expected) marginal net convenience yield or the level of inventories.

Finally, we consider our control for unexpected demand shocks. This is our third variable that we construct from commodity prices, and it will be a key variable in our modeling of cartel stability. It is derived as the difference

$$
E R_{t}=E_{t-1}\left(G P_{t}^{N Y}\right)-G P_{t}^{N Y} .
$$

Equation (7) turns out to be negative if the realization of the commodity price in New York at time $t$-a spot price at time $t$ in New York-exceeds its corresponding expectation formulated at time $t-1$. The error in the expectation variable, equation (7), will generate a difference between the expected and realized marginal net convenience yield, as well as the outside transportation rate. A negative error in expectations at time $t, E R_{t}<0$, that is, an unexpected jump in commodity prices, signs the inequalities $M N C Y_{t-1}^{E}>M N C Y_{t-1}$ and $G R_{t-1}^{* E}<G R_{t-1}^{*}$. From the point of view of railroads in the JEC, their shipments should have been greater (inventories should have been higher) and transportation rates higher for all modes of transportation. In monetary terms, the cartel lost an opportunity to extract higher revenues and reduce costs in the presence of economies of scale. This sort of event in the presence of imperfect information about other firms' actual price and shipments can trigger a finite revision to a low markup to maintain cooperation into the future, as modeled in Green and Porter (1984).

The analysis in this section has summarized the approach and data Porter and Ellison used. We have also noted our use of new data constructed from weekly commodity price data available in the New York Times. This includes our expected transportation rate (outside option to the JEC), the expected level of inventories in New York (negatively related to the marginal net convenience yield), and a realized error in the expectations of commodity prices in New York leading to mistakes in shipments and rate setting across all modes of transportation. These new variables allow us to control for the anticipated demand cycles and for realized mistakes created by unexpected demand shocks. We hope 
to get new insights into the determinants of JEC pricing, demand, and stability. The data on transportation prices on different modalities between Chicago and New York in the Aldrich Report (1893) were very useful in confirming the value of using the expected transportation rate, constructed from commodity prices. The Aldrich Report provides us with new data on JEC cartel adherence, our $P R$ variable. This will be important in our empirical methodology, as we treat cartel stability as observable. We justify this further in the next section, where we extend the structural model in Porter.

\section{The Model}

In this section we first reproduce the model and results of Porter. Step by step, we introduce our extensions and estimation procedure. Like Ellison, our extensions are done to tackle the instrumentation of marginal cost and to explore how best to model the markup term (cartel stability, among other factors) and the two components of the estimated pricing equation. Unlike Ellison, we employ a two-step semiparametric procedure that is largely motivated by the use of our commodity market data and our focus on the estimation of the time-varying markup driven by demand cycles, all else equal.

\section{A. Porter}

Porter specifies the following pricing equation, where lowercase letters denote natural logs of the variables:

$$
g r_{t}=\beta_{0[t]}+\beta_{1} q_{t}+\beta_{2} S_{t}+\beta_{3} I_{t}+U_{1 t},
$$

where $U_{1 t}$ is the error term, assumed NID with mean zero and variance $\sigma_{1}^{2}$. The first part of the pricing equation, $\beta_{0[t]}+\beta_{1} q_{t}+\beta_{2} S_{t}$, is the marginal cost associated with an average firm in the market at time $t$, whose particular specification is the result of the assumption of log linearity in each firm's heterogeneous cost functions. Porter denotes with $S_{t}$ a set of structural dummies that accommodate entry and exit and with $\beta_{0[t]}$ a constant augmented with month dummies. Marginal cost is modeled to depend on output, which needs to be instrumented. Porter estimates the following output equation,

$$
q_{t}=\alpha_{0[t]}+\alpha_{1} g r_{t}+\alpha_{3} L_{t}+U_{2 t},
$$

where $g r_{t}$ is the natural $\log$ of the JEC grain rate per bushel shipped in week $t$ and $q_{t}$ the natural log of the total quantity of grain shipped by railroad that week. ${ }^{11} L_{t}$ is a dummy equal to 1 when the Great Lakes are open to shipping and 0 otherwise. This is the variable (instrument) that is included in demand but not in the pricing equation. $U_{2 t}$ is the error term, assumed NID with mean zero and variance $\sigma_{2}^{2}$. The demand and pricing equation error terms are allowed to be correlated,

\footnotetext{
11 Given the possibility of secret price cutting, one can interpret $g r_{t}$ as a weighted average of list prices.
}

and their covariance is denoted with the parameter $\sigma_{12}$. The coefficient $\alpha_{1}$ is expected to be negative. The time-varying vector of coefficients $\alpha_{0[t]}$ encompasses a constant and month dummies.

The second component remaining in the pricing equation is the markup. Following the first-order condition for pricing, derived in Porter, the markup is equal to $-\ln \left(1+\theta_{t} / \alpha_{1}\right)$. In the Porter pricing equation, $\beta_{3} I_{t}=-\ln \left(1+\theta_{t} / \alpha_{1}\right)$, where $I_{t}$ is a dummy that equals 1 during a collusive regime, and 0 otherwise. This is motivated by Green and Porter (1984) to capture a time-varying average conduct parameter $\theta_{t}$. The market elasticity of demand is constant over time. We should expect $\beta_{3}$ to be positive in the term, $\beta_{3} I_{t}=-\ln \left(1+\theta_{t} / \alpha_{1}\right)$, as $\alpha_{1}$ is expected to be negative. The variation in the markup comes from the varying average conduct parameter. The key assumption is that there are only two discrete regimes in the markup - one that is collusive and one that is revisionary. Theory predicts that $\theta_{t}$ is higher during collusive regimes. We intend to model the markup as a nonparametric function of external demand cycles that drive week-on-week dynamics. This is a key departure from both Porter and Ellison in our modeling of markups, although Ellison does interact $I_{t}$ with indices of anticipated cycles, which moves a step toward our approach.

When $I_{t}$ is a known exogenous variable, using the $P O$ cheating variable collected by Ulen (1979), Porter estimates equations (8) and (9) using 2SLS. He estimates demand and pricing simultaneously and uses the exclusion restrictions observed in the defined pricing and output equations. We see that the Great Lakes dummy is excluded from the pricing equation, and the structural dummies and cartel breakdown dummy are excluded from the demand equation. Identification of the markup comes from an explicit functional form for both marginal cost and the markup term: $\beta_{3} I_{t}$. Porter felt that $P O$ was not very reliable and treated $I_{t}$ as an unknown. Hence, he estimated an endogenous switching (hidden) regime in the pricing equation over and above marginal cost following the procedure that originated in Lee and Porter (1984). ${ }^{12}$ This is how he constructed his estimated $P N$ binary variable.

\section{B. Aldrich Data on Cartel Stability}

As we mentioned in section II, we prefer the $P R$ binary variable, recovered from the Aldrich Report (1893), to reflect cartel stability or not. We wish to treat $P R$ as data, which will allow us to employ a two-step estimation procedure in our modeling of the markup. The expected probability of stability in the next period will be just one additional component of the markup. We intend to estimate this probability in a first stage and then condition the markup on it in a second step that estimates prices and output in a simultaneous equation.

The two-stage least squares (2SLS) and maximum likelihood (ML) estimates reported in columns 1 to 4 of table 4

\footnotetext{
12 In this case, the demand and pricing equation error terms are assumed to be normally distributed.
} 


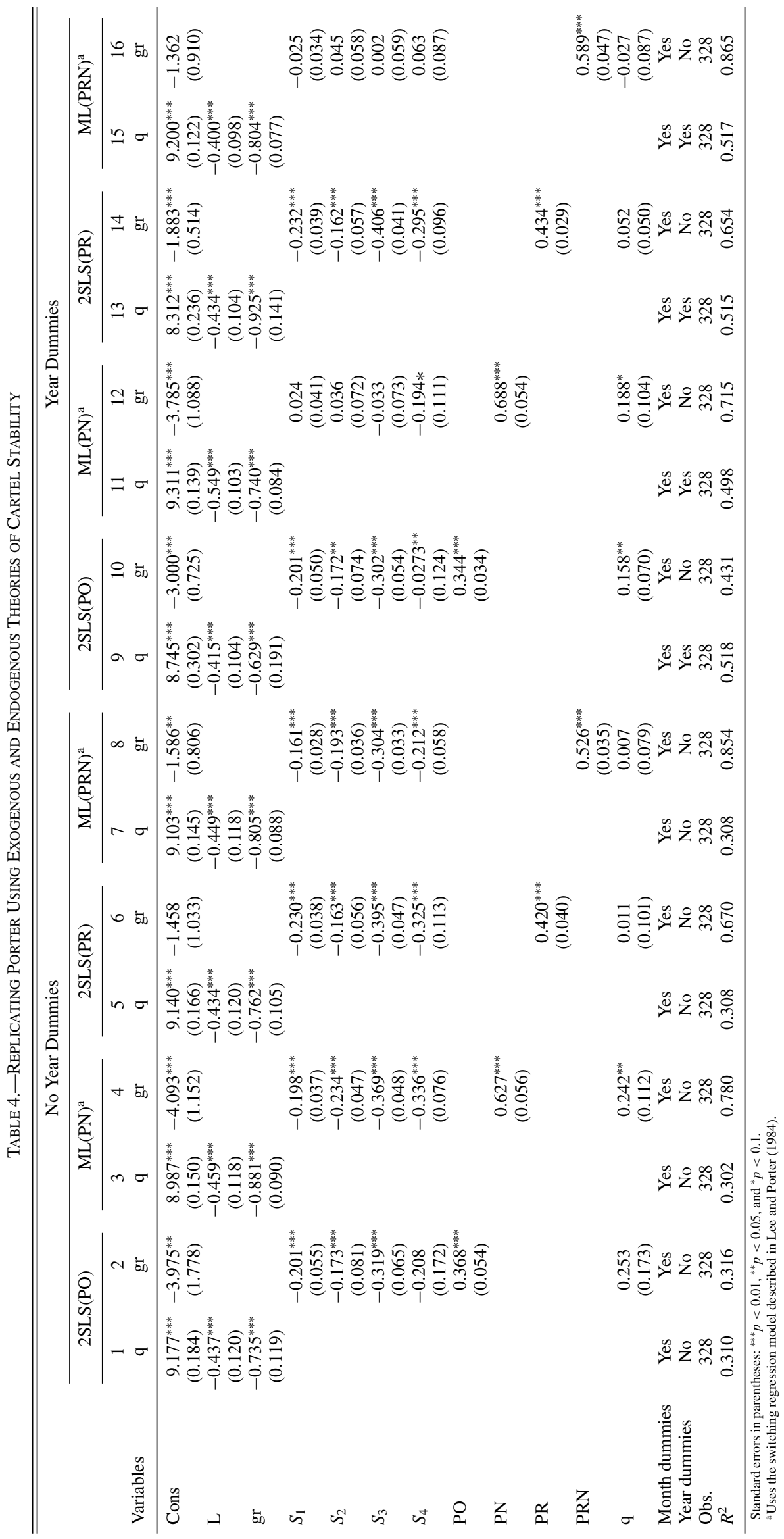


reproduce the results of Porter's table 3. Columns 5 to 8 repeat the estimations, but replace his variable $P O$ with our observed cheating variable, $P R$. The main aim of this exercise is to see whether $P R$ estimates the effect of the incidence of cheating in a similar way to $P N$, estimated endogenously in Porter. The employment of $P R$, instead of $P O$, raises the $R^{2}$ in the pricing equation from 0.32 in column 2 to 0.67 in column 6 , for the 2 SLS results. This is a lower value than the 0.78 in column 4 , when the hidden regime is endogenously estimated using $P O$ as the original variable, yet the ML estimator can increase the $R^{2}$ by even more to 0.85 in column 8 when using $P R$ as the initial variable to generate $P R N$. We run an independent two-sample Student's $t$-test and find that while the estimated constant elasticities of demand are similar, the estimated coefficients on the cartel stability dummy in the 2SLS and ML estimators are statistically different from one another, at the $5 \%$ significance level.

The subsequent columns, 9 to 16 , in table 4 are a rerun of the estimations in columns 1 to 8 , with the addition of year dummies as controls in the demand equation. Porter did not have year dummies in his specification. As expected, controlling for year dummies in demand strengthens the explanatory power of the demand side. Again we run an independent twosample Student's $t$-test and find the estimated coefficients on the cartel stability dummy in the 2SLS and ML estimators are statistically different from one another at the $5 \%$ significance level when using $P R$ instead of $P O$. We now find that the estimated constant elasticities of demand are different when $P R$ is used instead of $P O$.

When one compares columns 3 and 4 to columns 5 and 6, or columns 11 and 12 to columns 13 and 14, our 2SLS estimates using data on $P R$, our new variable, perform just as well as Porter's estimated $P N$. Although there will be slight differences in the incidence of price wars, we have shown now that these are similar variables. In section II, we reported basic summary statistics for $P O, P N, P R$, and $P R N$. While $P O$ is very different from the others, $P N, P R$, and $P R N$ are very similar. This is confirmed by figure 4 , where we graph the cumulated periods of cartel stability represented by these alternative measures of cartel stability. Hence, our use of $P R$ and inclusion of year dummies in the demand equation does not change the key Porter result. There is a hidden regime in the pricing equation that is clearly linked to the price wars that occurred intermittently in this cartel. Therefore, when we estimate our pricing equations, we choose to condition our modeling of the markup term on being in a regime of cartel stability or not as defined by $P R$, which we treat as an observable variable that does not need to be estimated.

\section{Further Extensions of Porter}

We extend Porter's pricing equation (8) in the following way:

$$
\begin{aligned}
g r_{t}= & \beta_{0[t]}+\beta_{1} q_{t}+\beta_{2} S_{t} \\
& +\Omega_{1}\left(g r_{t}^{* E}, N W C_{t}, N W O_{t}, E_{t}\left(P R_{t+1}\right)\right)+U_{1 t},
\end{aligned}
$$

Figure 4.-Cumulated Periods of CARTel Stability: PO, DAshed Line; PN, DotTED Line; PR, SOLID Line; PRN, DASHED-DOTTED LINE

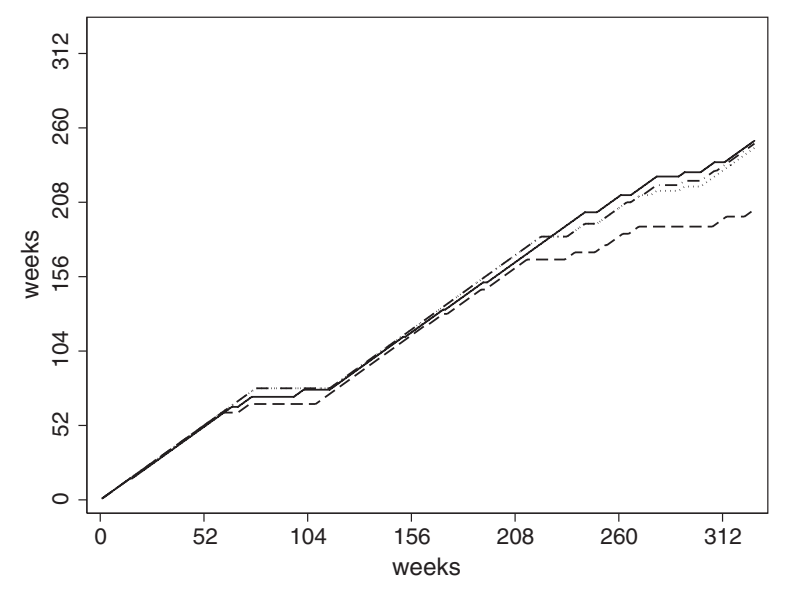

where $\beta_{0[t]}$ is the constant augmented with month dummies, defined earlier in section IIA. As in Porter, we specify as determinants of the marginal costs the sum of the error term and $\beta_{0[t]}+\beta_{1} q_{t}+\beta_{2} S_{t}$. Yet we instrument his marginal cost function by including additional previously omitted exogenous variables in the demand equation. We extend Porter's demand equation (9) in two ways. First, we expand the set of variables in the linear structure by introducing the expected price of the outside transportation mode. Second, we control for expected demand cycles using a nonparametric function. Ellison allows for hidden omitted variable regimes in demand and serial correlation in the demand residuals. We address these issues by including new control variables and a lagged dependent variable in demand to allow for partial adjustments. The demand equation that we estimate is

$$
\begin{aligned}
q_{t}= & \alpha_{0[t]}+\alpha_{1} g r_{t}+\alpha_{2} g r_{t}^{* E}+\alpha_{3} L_{t}+\alpha_{4} q_{t-1} \\
& +\Omega_{2}\left(M N C Y_{t}^{E}, N W C_{t}, N W O_{t}\right)+U_{2 t}
\end{aligned}
$$

Equation (11) depends on the own grain transportation rate and the expected rate of the outside transportation. $U_{2 t}$ is an independently distributed mean zero error term. Here the parameter $\alpha_{0[t]}$ includes a constant, month dummies and year dummies. To control for deterministic demand cycles, not captured by our price variables, we also include the covariates' number of weeks to the Great Lakes opening and number of weeks lakes reopen and a functional form of the expected marginal net convenience yield (which we have shown to be theoretically related to the level of inventories in New York) in the unspecified $\Omega_{2}$ function.

An additional clear point of departure is the way that we model the deterministic pricing component $\Omega_{1}(\cdot)$, Porter's hidden regime. Having an estimate of $\Omega_{1}(\cdot)$ we can back out the price-cost margin, $-\frac{\theta_{t}}{\eta}$, from the relation $\Omega_{1 t}=$ $-\ln \left(1+\theta_{t} / \eta\right)$, where $\eta$ is the total market constant elasticity 
defined as, $\eta \equiv \alpha_{1}+\alpha_{2} .{ }^{13}$ We model Porter's unobservable with observables that control for expected demand cycles and cartel stability: the expected pricing cycles from external competition, $g r^{* E}$, anticipated future demand cycles as we come towards Great Lakes closing and opening ( $N W C$ and $N W O$ ) and expectations of the cartel being stable one week ahead, $E_{t}\left(P R_{t+1}\right)$. We account for the effect on the markup of movements in anticipated future demand, as motivated by Haltiwanger and Harrington, through $g r^{* E}, N W C$ and $N W O .{ }^{14}$ We believe that our controls are approximations to the way that Gallet and Schroeter (1995) empirically relate the markup at time $t$ to the discounted expected value of future JEC collusive profits. This is a key ingredient that prevents cartel breakdown and allows the cartel to sustain a price over marginal cost.

Unlike Porter, we do not model the entire markup, $\Omega_{1 t}$ in pricing equation (10) as a revision to and from cartel stability but rather as a function of anticipated demand cycles whose effect the markup needs to be conditioned on, whether the cartel is stable or not. As a first step, we need to describe our model of the probability of cartel stability one period ahead. To allow for persistence in regimes and unobservable behavior, we model cartel stability as an $\operatorname{ARMA}(1,1)$ linear probability model,

$$
\begin{aligned}
P R_{t+1}= & \gamma_{0}+\gamma_{1} E L_{t}+\gamma_{2} E R_{t}+\gamma_{3} L_{t}+\gamma_{4} N_{t} \\
& +\gamma_{5} N W C_{t}+\gamma_{6} N W O_{t}+\gamma_{7} P R_{t}+U_{3, t+1}, \\
U_{3, t+1}= & \gamma_{8} V_{t}+V_{t+1} .
\end{aligned}
$$

The variable $V_{t+1}$ denotes a mean zero independently distributed innovation term. $P R$ set to 0 represents finite periods of revisions to noncollusive pricing. The interesting issue relates to what is triggering these periods of revisions, and that has been a focus of many empirical papers. We compete alternative theories against our new variables. As in Porter (1985) and Vasconcelos (2004), we account for the number of firms in the cartel, $N$, and for the opening and closing of the Great Lakes as internal factors that may affect the ICC. We add external controls for the countdown on number of weeks until the lakes reopen $(N W C)$ and the cumulated number of

\footnotetext{
13 The $\Omega_{1}(\cdot)$ function relates to the price-cost margin in the following way. $\Omega_{1 t}$ is the value of the nonparametric function defined in our log-log pricing equation (10), and $U_{1 t}$ is the mean zero additive error term part of the same equation. The expected value of a transformation of equation (10) gives us our relation of interest: $E\left(\ln \frac{G R_{t}}{C_{t}}\right)=-\ln \left(1+\frac{\theta_{t}}{\eta}\right) \equiv \Omega_{1 t}$. Once we recognize that $\ln \frac{G R_{t}}{C_{t}}=\ln \left(1+\frac{M U_{t}}{C_{t}}\right)$, where $M U_{t}$ denotes the markup and $C_{\hat{t}}$ the marginal cost, we can simplify the notation further and define $W_{t} \equiv \frac{M U_{t}}{C_{t}}$. Now we recall that the Taylor series of the function $\ln \left(1+W_{t}\right)$ gives $\ln \left(1+W_{t}\right)=W_{t}-\frac{W_{t}^{2}}{2}+\frac{W_{t}^{3}}{3}+O\left(W_{t}^{4}\right)$. For low absolute values of $W_{t}$, the left-hand side can be approximated by the term $W_{t}$ itself. In our context, this means that the nonparametric function $\Omega_{1}$ is an approximation of the price-cost margin normalized to the marginal cost. This will be the way we interpret it.

14 We capture exogenous movements in current demand using the price $g r^{* E}$, month dummies, and endogenous movements in current demand are accounted for through the marginal cost component. $N W C$ and $N W O$ may reflect just week effects in current demand, but the controls are consistent with and do control for the effects of expected future demand.
}

weeks that lakes remain open $(N W O)$ to control for the effect of anticipated deterministic cycles modeled in Haltiwanger and Harrington. We also include, one at a time, the set of Ellison's triggers $(E L)$ that reflect internal conflict, thus controlling for unusual movements in firm-level market shares. Finally, we introduce our new variable that captures realized errors in past expectations of corn prices in New York $(E R)$, as defined in equation (7). Negative errors reveal a situation where the elevators in New York should have been transporting more at a higher rate over all modes of transportation. This creates a scene where the JEC is likely to have simultaneously lost the opportunity to transport more and price higher in the last period. The firms in the railroad cartel observe a boom in New York commodity prices but realize that they did not get the reward. In the presence of imperfect observation of the output and prices in other firms, this could force an unstable ICC and a period of finite competitive prices to discipline the cartel, as modeled in Green and Porter (1984). We put forward realized and unexpected past mistakes in commodity market price forecasts as the key factor that can threaten the cartel's stability.

As displayed in equation (10), we have conditioned the $\Omega_{1}(\cdot)$ function in the pricing equation on the expected cartel stability one period ahead. The expectation of cartel stability one period ahead raises concern over a possible correlation between the error terms in the system of pricing and output equations and the components of the expectation of cartel stability one period ahead. These components include Ellison's variables, the lagged error term in the cartel equation, $V_{t}$, the current cartel stability variable $P R_{t}$, and our new variable that captures realized errors in past expectations of grain prices in New York $(E R)$. It will turn out that the forward expectations on cartel stability one period ahead will depend strongly on the presence of backward-looking realized mistakes in the expectations of New York grain commodity prices. Mistakes in the past trigger a negative forward look that is modeled to persist and fade out over a finite spell. Such mistakes are externally driven by realized differences in yesterday's future and today's spot grain prices in New York. These mistakes are compelled by conditions external to the cartel, such as an unexpected boom in the European market. These are fully exogenous and are not expected to affect current pricing and output setting in the JEC, but they can destabilize the JEC in the next period and affect future pricing. The other variables turn out not to be significant in modeling cartel stability.

We hope to model our first step with a set of factors that are orthogonal to the errors in the pricing and output system of equations. The markup $\Omega_{1}$ function will be computed in a second step where we estimate the demand and pricing system together. $\Omega_{1}$ is modeled to be the deterministic part of pricing over and above our imposed linear model of the natural log of marginal cost. Markups are easily derived: they are a nonparametric deterministic residual over and above the Porter natural log of marginal cost parametric specification. Thus, the only identification that we need to focus 
on is that of a classical simultaneous demand and supply relation. The exclusion restrictions that we employ to identify the endogenous (natural log of the) rate of transportation in demand are cost shifters, such as the structural dummies used in Porter, and a markup shifter, which differs from Porter's, as we employ the predicted probability of the cartel being stable one period ahead rather than its observed current binary realization. As mentioned above, the latter is a function of the set of exogenous variables displayed in equation (12). Both types of shifters are correlated with the rate of transportation. To deal with the endogeneity of (the natural log of) quantity in the pricing equation, we employ as exclusion restrictions the demand shifters such as year dummies and the expectation of the marginal net convenience yield. We estimate our model with both a 2SLS estimator and an adjusted (to deal with endogeneity) Robinson's (1988) estimator. The former methodology relies on a linearization of the $\Omega_{1}$ and $\Omega_{2}$ nonparametric functions. We have deliberately chosen to estimate a linearized version of the nonparametric functions to better inspect and understand the partial contributions of each variable. Yet unspecified nonlinear interactions lead to a better modeling of our endogenous variables and greater confidence, statistical and otherwise, in our estimated markup cycles that will be shown to have interesting properties. Here we have described the identification for the simplified linearized case. (Refer to the online appendix for the econometric identification of the more cumbersome semiparametric approach.)

\section{Results}

We present our results in three steps. In step 1, we estimate the weekly forward look on the probability of cartel stability in the next period. In step 2, while conditioning the markup on the probability of cartel stability in the next period, we estimate the weekly price-cost and profit cycles for the JEC in a simultaneous equation model for pricing and demand. Finally, in step 3, we model the cyclical nature of our estimated markups.

\section{A. Step 1: Modeling Cartel Instability}

Table 5 reports the estimates of the ARMA $(1,1)$ linear probability specification that we have modeled in equation (12). The table highlights persistence in the state of the dependent variable, as indicated by the high value of the $\gamma_{7}$ parameter. Once a shock brings the dependent variable from a state of stability to one of instability, it will take a number of weeks before it goes back to stability, showing evidence of Green and Porter's (1984) theory of finite periods of punishments. The span of instability is embedded in the intensity of the shock that has caused the drifting away and in realizations of other opposite (in sign) future shocks.

Another key variable that is significant in explaining cartel stability one period ahead is the realized mistake in expectations of the commodity price in New York introduced in

\begin{tabular}{|c|c|c|c|c|c|}
\hline \multirow[b]{2}{*}{ Variables } & \multicolumn{5}{|c|}{$\mathrm{PR}_{+1}(=1$ Stability $)$} \\
\hline & 1 & 2 & 3 & 4 & 5 \\
\hline Cons & $\begin{array}{l}1.141^{* * *} \\
(0.310)\end{array}$ & $\begin{array}{l}1.127^{* * *} \\
(0.311)\end{array}$ & $\begin{array}{l}1.120^{* * *} \\
(0.309)\end{array}$ & $\begin{array}{l}1.143^{* * *} \\
(0.310)\end{array}$ & $\begin{array}{l}1.103^{* * *} \\
(0.311)\end{array}$ \\
\hline $\mathrm{N}$ & $\begin{array}{c}-0.051 \\
(0.072)\end{array}$ & $\begin{array}{c}-0.055 \\
(0.073)\end{array}$ & $\begin{array}{c}-0.058 \\
(0.074)\end{array}$ & $\begin{array}{c}-0.046 \\
(0.071)\end{array}$ & $\begin{array}{c}-0.054 \\
(0.075)\end{array}$ \\
\hline $\mathrm{L}$ & $\begin{array}{c}-0.311 \\
(0.181)\end{array}$ & $\begin{array}{r}-0.307^{*} \\
(0.181)\end{array}$ & $\begin{array}{c}-0.301 \\
(0.184)\end{array}$ & $\begin{array}{c}-0.310 * \\
(0.182)\end{array}$ & $\begin{array}{r}-0.314^{*} \\
(0.180)\end{array}$ \\
\hline NWO & $\begin{array}{c}0.005 \\
(0.008)\end{array}$ & $\begin{array}{c}0.005 \\
(0.008)\end{array}$ & $\begin{array}{c}0.006 \\
(0.008)\end{array}$ & $\begin{array}{c}0.006 \\
(0.008)\end{array}$ & $\begin{array}{c}0.006 \\
(0.008)\end{array}$ \\
\hline NWC & $\begin{array}{c}-0.005 \\
(0.009)\end{array}$ & $\begin{array}{c}-0.004 \\
(0.009)\end{array}$ & $\begin{array}{c}-0.003 \\
(0.009)\end{array}$ & $\begin{array}{c}-0.004 \\
(0.009)\end{array}$ & $\begin{array}{c}-0.004 \\
(0.009)\end{array}$ \\
\hline ER & $\begin{array}{l}0.570^{* * *} \\
(0.218)\end{array}$ & $\begin{array}{l}0.561^{* * *} \\
(0.219)\end{array}$ & $\begin{array}{l}0.572^{* * *} \\
(0.215)\end{array}$ & $\begin{array}{l}0.570^{* * *} \\
(0.218)\end{array}$ & $\begin{array}{l}0.565^{* * * *} \\
(0.214)\end{array}$ \\
\hline BIG1 & & $\begin{array}{c}0.026 \\
(0.034)\end{array}$ & & & \\
\hline BIG2 & & & $\begin{array}{c}0.030 \\
(0.023)\end{array}$ & & \\
\hline BIGQ & & & & $\begin{array}{c}-0.016 \\
(0.024)\end{array}$ & \\
\hline SMALL1 & & & & & $\begin{array}{c}0.042 \\
(0.026)\end{array}$ \\
\hline$P R$ & $\begin{array}{l}0.787^{* * *} \\
(0.051)\end{array}$ & $\begin{array}{l}0.789^{* * *} \\
(0.051)\end{array}$ & $\begin{array}{l}0.786^{* * *} \\
(0.051)\end{array}$ & $\begin{array}{l}0.785^{* * *} \\
(0.053)\end{array}$ & $\begin{array}{l}0.794^{* * *} \\
(0.051)\end{array}$ \\
\hline V & $\begin{array}{c}0.046 \\
(0.062)\end{array}$ & $\begin{array}{c}0.040 \\
(0.064)\end{array}$ & $\begin{array}{c}0.043 \\
(0.064)\end{array}$ & $\begin{array}{c}0.045 \\
(0.063)\end{array}$ & $\begin{array}{c}0.023 \\
(0.066)\end{array}$ \\
\hline Month dummies & No & No & No & No & No \\
\hline Year dummies & No & No & No & No & No \\
\hline Observations & 319 & 318 & 318 & 318 & 318 \\
\hline$R^{2}$ & $296 / 319$ & $295 / 318$ & $295 / 318$ & $295 / 318$ & $295 / 318$ \\
\hline Obs. $\hat{P R} R_{+1}<0$ & $1 / 319$ & $1 / 318$ & $1 / 318$ & $1 / 318$ & $1 / 318$ \\
\hline Obs. $\hat{P R}_{+1}>1$ & $45 / 319$ & $53 / 318$ & $45 / 318$ & $51 / 318$ & $58 / 318$ \\
\hline ll & -11.691 & -11.620 & -11.029 & -11.863 & -10.232 \\
\hline
\end{tabular}

Robust standard error in parentheses. ${ }^{* * *} p<0.01,{ }^{* *} p<0.05$, and ${ }^{*} p<0.1$. We
method that switches between the BHHH and the BFGS optimization algorithms.

equation (7). If the error ends up being negative, the spot price at time $t$ in New York would prove to be higher than that expected at time $t-1$. We showed in section II how that relates to a realized mistake in the expected marginal net convenience yield and the expected outside transportation rate that the cartel was optimizing against in the previous period. The JEC railroad should have been setting higher prices and transporting more volume than it actually was. Setting a rate below the optimal level under certainty can be seen as a destabilizing force, particularly if each firm observes a boom but makes losses and is uncertain about the pricing and output of other firms in the cartel. We quantify the intensity of the effect as follows: 1 standard deviation reduction in the error in expectation will increase the cartel instability by over $3 \%$, in the short run and by over $15 \%$ in the long run, all else equal. We find clear evidence that unexpected demand shocks in corn markets in New York, which lead to mistakes in a historical price setting, triggered instability in the JEC. This is consistent with Green and Porter (1984) and is similar to a finding in Ellison (1994), who worked with the random part of the demand residual to model unexpected demand shocks. We have gone a step further and linked it to realized mistakes in the expectations of corn market prices in New York, leading to suboptimal inventory management and price setting in the whole transportation sector. 
Anticipated demand cycles, the countdown on the number of weeks until the Great Lakes reopen, $N W C$, and the cumulated number of weeks that the lakes remain open, NWO, which control for the effect of anticipated deterministic cycles modeled in Haltiwanger and Harrington, are insignificant. This is also consistent with the findings of Ellison, who used different endogenous indices to control for expected demand, including the autocorrelated demand residuals, among other components. The same important result, that demand shocks and unanticipated cycles were the key drivers of cartel instability, emerges. This supports the theory of Green and Porter (1984).

As in Porter (1985) and Vasconcelos (2004), we account for the number of firms in the cartel and for the opening and closing of the Great Lakes as factors affecting the ICC constraint. In contrast to them, the number of firms is never significant in our model, and the probability of cartel instability is more likely to happen in the lakes open regime. A feature of the lakes open regime is that the demand tends to be low for the JEC up to the harvesting and then increases rapidly up to lakes closing. We estimate that profits for the JEC were normally highest in the latest weeks of lakes open, when both prices and shipments increased. Finally, we include the set of triggers used in Ellison and find, as he did, that unusual movements in market shares inside the JEC were not as important as the common external demand shocks that came from New York, which all firms faced.

We argued in the previous section that an unexpected boom in the New York commodity market is likely to be driven by conditions external to the cartel. Advancing this notion, our modeling of the probability of cartel breakdown is mainly driven by an exogenous shock that should not affect current pricing and output setting in the JEC but can destabilize the JEC in the next period and beyond. We turn to estimating the markup where we condition its $\Omega_{1}$ function on the estimated probability of cartel stability one period ahead, which is driven by an external demand shock to commodity prices in New York and a strong path dependency.

\section{B. Step 2: Estimating Markup and Profit}

We estimate markup and profit dynamics for the JEC using a standard simultaneous equations model for demand and pricing equations. We instrument output as a component of the marginal cost in pricing. In addition, the markup component of pricing is conditioned on the probability of the cartel's remaining in a collusive regime in the next time period. We use the specification displayed in column 5 of table 5 to compute the predicted probability of cartel stability $\hat{P R}_{t+1}$, which we incorporate in our modeling of $\Omega_{1}(\cdot)$ in the regressions documented in table 6 .

In the 2SLS columns for the baseline model in table 6, we linearize the $\Omega_{1}(\cdot)$ function in the pricing equation and the $\Omega_{2}(\cdot)$ function in the demand equation. We can think of this as a polynomial of order 1 in the variables that enter the two functions. This has the advantage that it simplifies the estimator to a 2SLS approach that, given the use of year dummies, can be compared to the results documented in columns 13 and 14 in table 4 . We can judge whether these new control variables have interesting partial effects in terms of sign, magnitude, and significance. The downside is that we are missing out on potentially interesting interactions between the variables in these functions. For example, our controls for deterministic cycles in $\Omega_{1}(\cdot)$, which are $g r^{* E}, N W C$, and $N W O$, could have an impact on JEC rate setting very differently when interacted with the predicted probability of cartel stability, $\hat{P R} R_{t+1}$. Hence we also estimate and document the results of using a semiparametric estimation for this baseline model.

We now discuss the results for the baseline model, beginning with the demand equation. Our variable, $g r^{* E}$, which controls for the expected rate on alternative modes of transportation, is significant in demand. An increase in the grain rate of the alternative modes of transportation increases demand for shipments by the cartel. Of the variables in the $\Omega_{2}(\cdot)$ part of the demand specification, only positive spikes in the marginal convenience yield have a significant partial effect. We interpret this particular effect as evidence of the urgent need of grain elevators to top up their inventories. Normally, demand cycles created by elevators should be reflected in expected transportation prices. When inventories fall below a designated threshold, the demand for the commodity can spike and lead to higher demand for the railroad to transport grain immediately to New York. With the contribution of the partial effect of $D M N C Y H^{E}$, we do not reject at the 5\% level the joint significance of the coefficients of variables that make $\Omega_{2}(\cdot)$. However, $\Omega_{2}(\cdot)$ explains on its own only about $15 \%$ of the variation in demand.

In the pricing equation, all our new variables in $\Omega_{1}(\cdot)$ are significant. All things equal, the accumulation of weeks to lakes closing, $N W O$, puts upward pressure on pricing, while the loss of weeks to lakes reopening, $N W C$, puts downward pressure on prices. The expected rate of the outside transportation option, $g r^{* E}$, creates an upward pressure on price. We see the JEC as a price follower in this optimal response function. The estimated probability of stability, $\hat{P R}_{t+1}$, is significant and has an important positive effect on pricing.

This baseline model is also estimated using a semiparametric 2SLS estimation method to allow $\Omega_{1}(\cdot)$ in pricing and $\Omega_{2}(\cdot)$ in demand to be estimated nonparametrically. We adjust Robinson's (1988) difference estimator in order to account for the endogeneity in the system of simultaneous equations (see the online appendix for details on the estimator). The results from this semiparametric estimation for the baseline model are presented in columns 3 and 4 of table 6 . The sum of the own- and cross-price elasticities is now estimated to be lower than those computed with the linear $2 S L S$ estimator. The $\Omega_{1}(\cdot)$ function is computed to be a bigger deterministic component as the overall explanatory power of the supply relation has increased from 0.685 to 0.870 due to implicit interactions between the variables in the $\Omega_{1}(\cdot)$ function. Comparing the coefficient of determination with and without $\Omega_{1}(\cdot)$, we note 


\begin{tabular}{|c|c|c|c|c|c|c|c|c|}
\hline \multirow[b]{4}{*}{ Variables } & \multicolumn{4}{|c|}{ Baseline Model } & \multicolumn{4}{|c|}{ Partial Adjustment Model ${ }^{\mathrm{a}}$} \\
\hline & \multicolumn{2}{|c|}{ Linear 2SLS } & \multicolumn{2}{|c|}{ Semiparametric 2SLS } & \multicolumn{2}{|c|}{ Linear 2SLS } & \multicolumn{2}{|c|}{ Semiparametric 2SLS } \\
\hline & 1 & 1 & 3 & 4 & 5 & 6 & 7 & 8 \\
\hline & $\mathrm{q}$ & gr & $\mathrm{q}$ & gr & $q$ & gr & $\mathrm{q}$ & gr \\
\hline Cons & $\begin{array}{l}8.389^{* * *} \\
(0.421)\end{array}$ & $\begin{array}{c}-2.346^{* * *} \\
(0.479)\end{array}$ & & & $\begin{array}{l}2.815^{* * *} \\
(0.468)\end{array}$ & $\begin{array}{c}-1.127^{* * *} \\
(0.326)\end{array}$ & & \\
\hline $\mathrm{L}$ & $\begin{array}{c}-0.529^{* * *} \\
(0.123)\end{array}$ & & $\begin{array}{r}-0.106 \\
(0.286)\end{array}$ & & $\begin{array}{c}-0.260^{* * *} \\
(0.093)\end{array}$ & & $\begin{array}{c}-0.102 \\
(0.216)\end{array}$ & \\
\hline NWC & $\begin{array}{c}-0.013 \\
(0.013)\end{array}$ & $\begin{array}{l}0.023^{* * *} \\
(0.006)\end{array}$ & & & $\begin{array}{c}-0.005 \\
(0.009)\end{array}$ & $\begin{array}{l}0.022^{* * *} \\
(0.006)\end{array}$ & & \\
\hline NWO & $\begin{array}{c}0.011 \\
(0.009)\end{array}$ & $\begin{array}{l}0.018^{* * *} \\
(0.004)\end{array}$ & & & $\begin{array}{c}0.013^{*} \\
(0.007)\end{array}$ & $\begin{array}{l}0.016^{* * *} \\
(0.004)\end{array}$ & & \\
\hline $\mathrm{MNCY}^{E}$ & $\begin{array}{c}-1.768 \\
(1.256)\end{array}$ & & & & $\begin{array}{c}-0.304 \\
(0.918)\end{array}$ & & & \\
\hline $\mathrm{DMNCYH}^{E \mathrm{~b}}$ & $\begin{array}{l}0.580^{* *} \\
(0.237)\end{array}$ & & & & $\begin{array}{c}0.168 \\
(0.176)\end{array}$ & & & \\
\hline $\mathrm{DMNCYL}^{E \mathrm{c}}$ & $\begin{array}{c}0.057 \\
(0.214)\end{array}$ & & & & $\begin{array}{r}-0.043 \\
(0.157)\end{array}$ & & & \\
\hline $\mathrm{gr}$ & $\begin{array}{c}-1.108^{* * *} \\
(0.196)\end{array}$ & & $\begin{array}{c}-0.916^{* * *} \\
(0.186)\end{array}$ & & $\begin{array}{c}-0.553^{* * *} \\
(0.162)\end{array}$ & & $\begin{array}{c}-0.419^{* * *} \\
(0.162)\end{array}$ & \\
\hline $\mathrm{gr}^{* E}$ & $\begin{array}{l}0.117^{* *} \\
(0.059)\end{array}$ & $\begin{array}{l}0.112^{* * *} \\
(0.024)\end{array}$ & $\begin{array}{l}0.105^{* *} \\
(0.052)\end{array}$ & & $\begin{array}{l}0.085^{* *} \\
(0.043)\end{array}$ & $\begin{array}{l}0.107^{* * *} \\
(0.023)\end{array}$ & $\begin{array}{c}0.056^{*} \\
(0.035)\end{array}$ & \\
\hline $\mathrm{q}$ & & $\begin{array}{c}0.067 \\
(0.044)\end{array}$ & & $\begin{array}{r}-0.021 \\
(0.042)\end{array}$ & & $\begin{array}{r}-0.049^{*} \\
(0.029)\end{array}$ & & $\begin{array}{c}-0.067^{* *} \\
(0.032)\end{array}$ \\
\hline$q_{-1}$ & & & & & $\begin{array}{l}0.638^{* * *} \\
(0.050)\end{array}$ & & $\begin{array}{l}0.645^{* * *} \\
(0.059)\end{array}$ & \\
\hline$\hat{P R}+1$ & & $\begin{array}{l}0.434^{* * *} \\
(0.035)\end{array}$ & & & & $\begin{array}{l}0.395^{* * *} \\
(0.032)\end{array}$ & & \\
\hline$S_{1}$ & & $\begin{array}{c}-0.228^{* * *} \\
(0.042)\end{array}$ & & $\begin{array}{r}-0.017 \\
(0.019)\end{array}$ & & $\begin{array}{c}-0.227^{* * *} \\
(0.040)\end{array}$ & & $\begin{array}{r}-0.019 \\
(0.020)\end{array}$ \\
\hline$S_{2}$ & & $\begin{array}{c}-0.142^{* *} \\
(0.057)\end{array}$ & & $\begin{array}{c}0.036 \\
(0.026)\end{array}$ & & $\begin{array}{c}-0.143^{* * *} \\
(0.054)\end{array}$ & & $\begin{array}{c}0.047^{*} \\
(0.027)\end{array}$ \\
\hline$S_{3}$ & & $\begin{array}{c}-0.370^{* * *} \\
(0.045)\end{array}$ & & $\begin{array}{c}-0.056^{* * *} \\
(0.020)\end{array}$ & & $\begin{array}{c}-0.344^{* * *} \\
(0.042)\end{array}$ & & $\begin{array}{c}-0.051^{* *} \\
(0.021)\end{array}$ \\
\hline$S_{4}$ & & $\begin{array}{c}-0.245^{* * *} \\
(0.091)\end{array}$ & & $\begin{array}{c}-0.047 \\
(0.049)\end{array}$ & & $\begin{array}{c}-0.331^{* * *} \\
(0.085)\end{array}$ & & $\begin{array}{r}-0.083^{*} \\
(0.046)\end{array}$ \\
\hline Month dummies & Yes & Yes & Yes & Yes & Yes & Yes & Yes & Yes \\
\hline Year dummies & Yes & No & Yes & No & Yes & No & Yes & No \\
\hline Observations & 312 & 312 & 312 & 312 & 312 & 312 & 312 & 312 \\
\hline$R^{2}$ & 0.515 & 0.685 & 0.554 & 0.870 & 0.741 & 0.712 & 0.748 & 0.875 \\
\hline$R_{-\Omega}^{2 \mathrm{~d}}$ & 0.367 & -0.041 & 0.318 & 0.051 & 0.631 & 0.113 & 0.701 & 0.061 \\
\hline P-value $F$-test coefficients in $\Omega$ & $0.043^{* *}$ & $0.000^{* * *}$ & & & 0.196 & $0.000^{* * *}$ & & \\
\hline
\end{tabular}

the dominant role of the markup function, which explains on its own almost all of the pricing equation. ${ }^{15}$

Ellison allows for serial correlation in the demand equation. To improve the overall explanatory power of the demand equation, instrument marginal cost, and get better estimates of price elasticities, we factor in demand as a partial adjustment model. The structure in the demand equation suggests that we do not control for differences in actual rates (which change daily) and the official rate (set weekly) well enough, and we should allow for a one-week partial adjustment. Our results for this model using a 2SLS estimator of our linear

\footnotetext{
${ }^{15}$ Note that the $R^{2}$ can be negative in the 2SLS estimator, for some of the regressors enter in the model as instruments for the endogenous variables. However, when the model is fitted, the actual values of the endogenous variables, not the instruments, are used. The implication is that the sum of squares is no longer constrained to be smaller than the total sum of squares.
}

modeling are presented in columns 5 and 6 of table 6 and its semiparametric version in columns 7 and 8 . The parameters and standard errors have to be divided by $\left(1-\hat{\alpha}_{4}\right)$ to be comparable to those of the baseline model. The explanatory power of the demand model is now 0.74 . More important, we see that the sums of the adjusted own- and cross-price elasticities are (in absolute value) higher when compared to the baseline model. The explanatory power of $\Omega_{2}$ now accounts for only $11 \%$ of total variation in demand. We also observe some changes in our pricing side. The linear modeling of $\Omega_{1}(\cdot)$ shows that the expected outside transportation rate and the estimated cheating probability has a bigger effect. Output in marginal cost is displaying some economies of scale. Unlike the earlier literature, having controlled effectively for the omitted variables and partial adjustment in our modeling of demand, we now observe economies of scale 
Figure 5.-Estimated Price-Cost Margin and Profit (Dashed Line), And Estimated Price-Cost Margin and Profit Business Cycles (Bold Curved Line), Cartel Instability Period $(P R=0$, Triangle at 0$)$, Lakes Open $(L=1$, Diamond at .5 or 1$)$
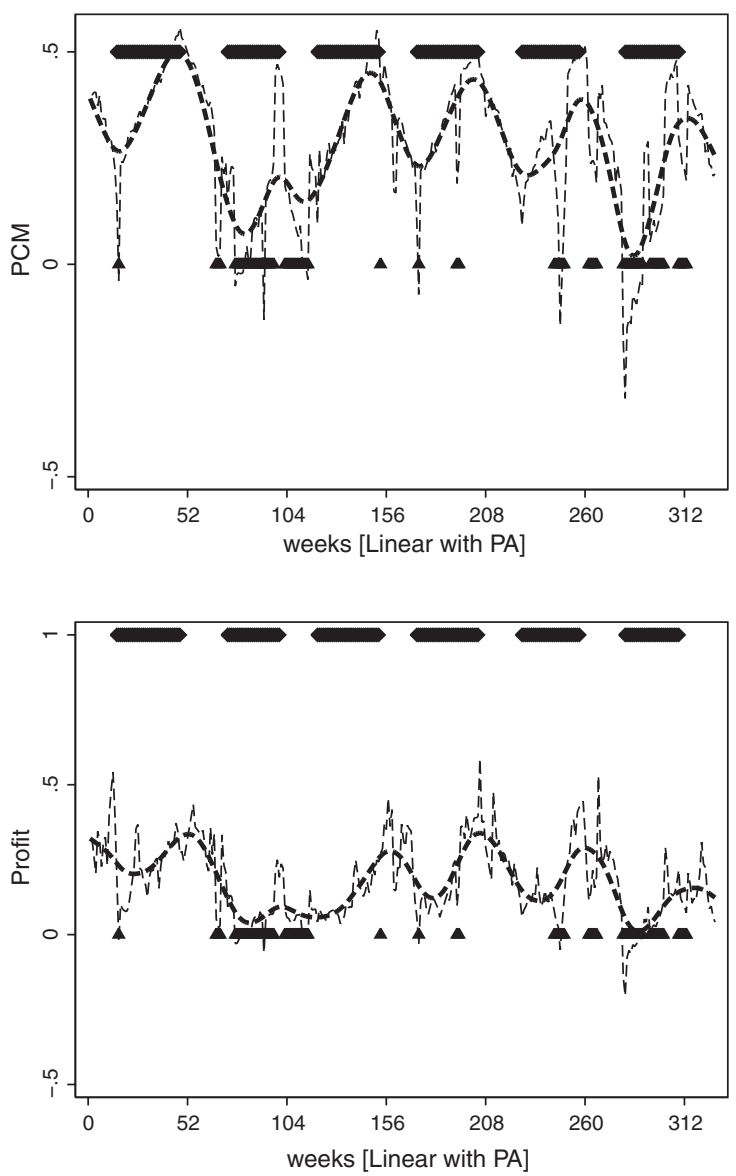

in marginal costs. 16 While Fabra (2006) shows us that the results of Haltiwanger and Harrington would be less likely to hold in industries with capacity constraints, economies of scale theoretically reinforce the mechanisms in Haltiwanger and Harrington, since when demand is expected to be high, marginal costs are expected to be low. A threat of a revision to a zero profit becomes more binding as expected demand rises and less binding as expected demand falls. The explanatory power of the pricing equation increases to 0.87 when estimated semiparametrically. Our $\Omega_{1}(\cdot)$ function maintains its high explanatory power, explaining about $80 \%$ of the pricing equation in the semiparametric approach.

Our estimated price-cost margin dynamics are calculated using the estimated $\hat{\Omega}_{1}(\cdot)$ in the pricing equation. The top two graphs of figure 5 are plots of the estimated price-cost margins for the partial adjustment model, $-\frac{\hat{\theta}_{t}}{\hat{n}}$, overlapped by their smoothed cycles (computed using Hodrick and Prescott's, 1997, filter). The estimates of the price-cost margin are plotted over the lakes open and closed periods and against periods of cartel instability as defined by our $P R=0$ variable. The bottom two graphs are the corresponding plots of estimated

16 Walters (1967) has surveyed estimates of cost functions in 34 industries and found evidence of constant or increasing returns to scale.
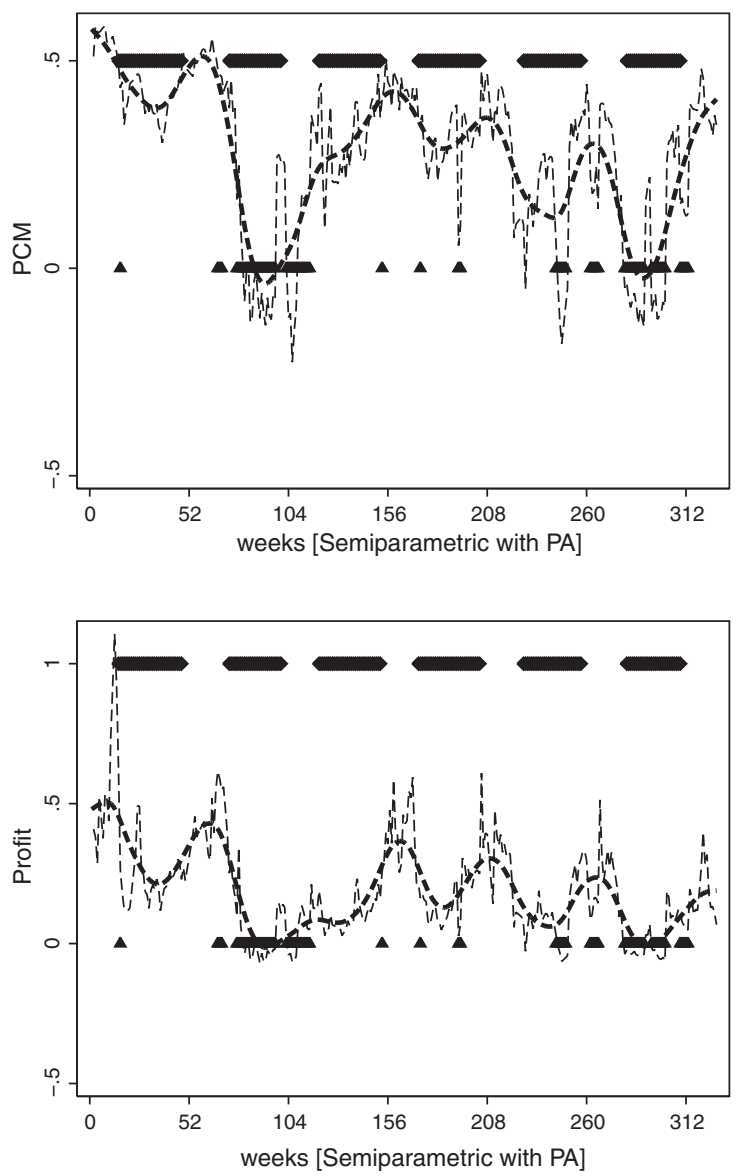

profit (overlapped by their smoothed cycles). ${ }^{17}$ Given that the graphs of the baseline model are very similar to those of the partial adjustment model we do not include them in figures 5, 6 , and 7.

The estimated cycles for the Linear and Semi-parametric model are reasonably similar in trends but differ in levels. Clearly, the weeks of cartel instability are associated with unusually low mark-ups and profits for the cartel in both models. Railroads made losses over some spells when $P R$ was zero. Our semi-parametric estimation of the partial adjustment model of demand with supply relation suggests that the cartel actually incurred sustained losses during these periods. In periods of stability we do see some interesting "stylized" cycles emerging. In lakes closed regimes we see price-cost margins drop as lakes reopening approaches. While mark-ups are low at the start of lakes open they consistently rise over the period. More importantly, looking at profit cycles, the periods coming to the end of lakes open normally generated the highest weekly profits for the cartel. The race against the clock in inventory management normally induced increases on the outside transportation rates (captured by $g r^{* E}$ ), hence

\footnotetext{
17 Cartel profit is computed as markup times quantity and is expressed in tens of thousands of dollars.
} 
Figure 6.-Normalized Quantity Business Cycles (Dashed Line) and Estimated Price-Cost Margin and Profit Business Cycles (Solid Lines). The Triangle at 0 Denotes Cartel Instability; the Diamond at .5 Denotes Lakes Open
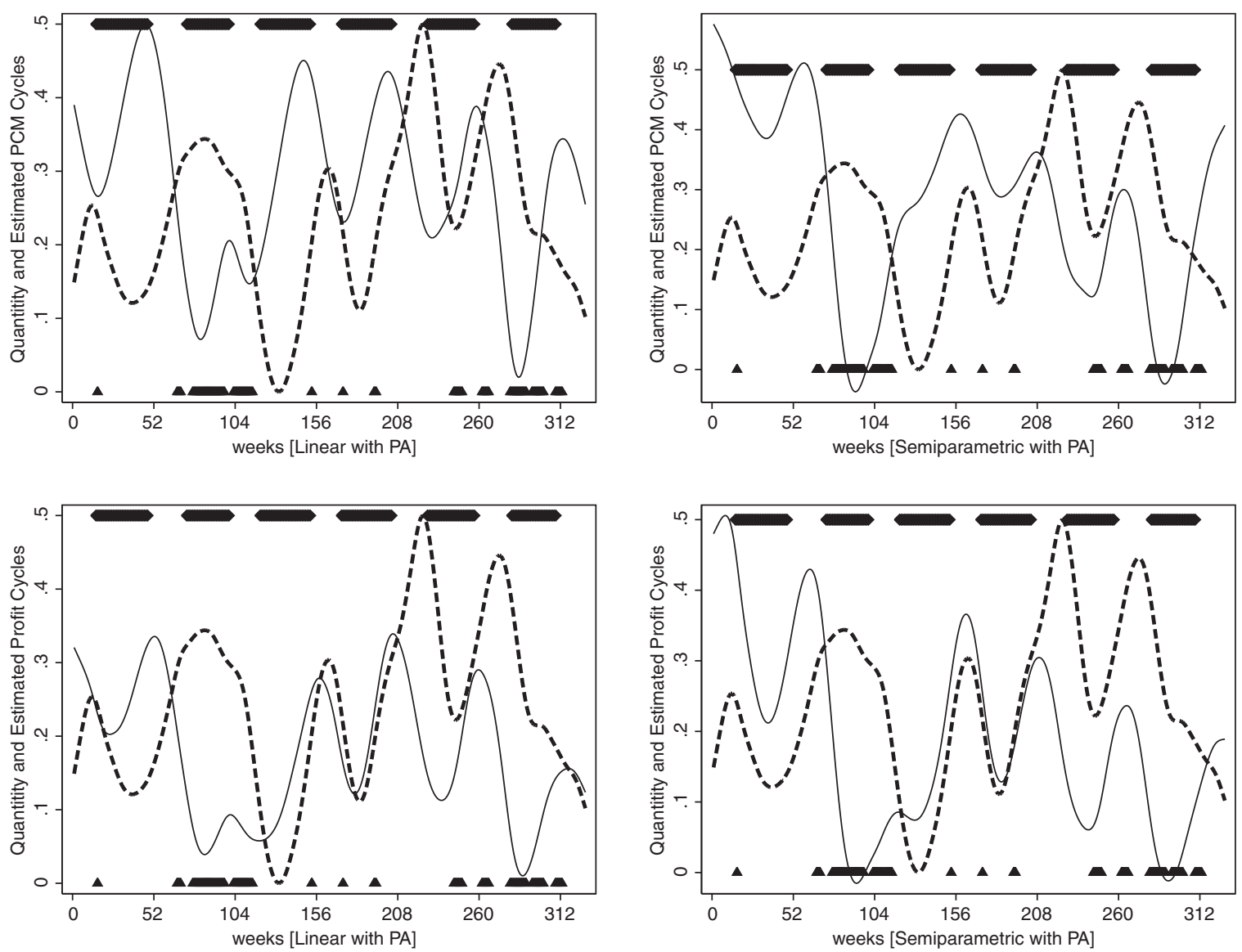

FIGURE 7.-ESTIMATED PRICE-COST MARGIN BOOMS (SOLID LINES) AND PRICE-COST MARGIN RECESSIONS (DASHED LINES) BY QUANTITY BUSINESS CYCLE AND NUMBER OF FIRMS

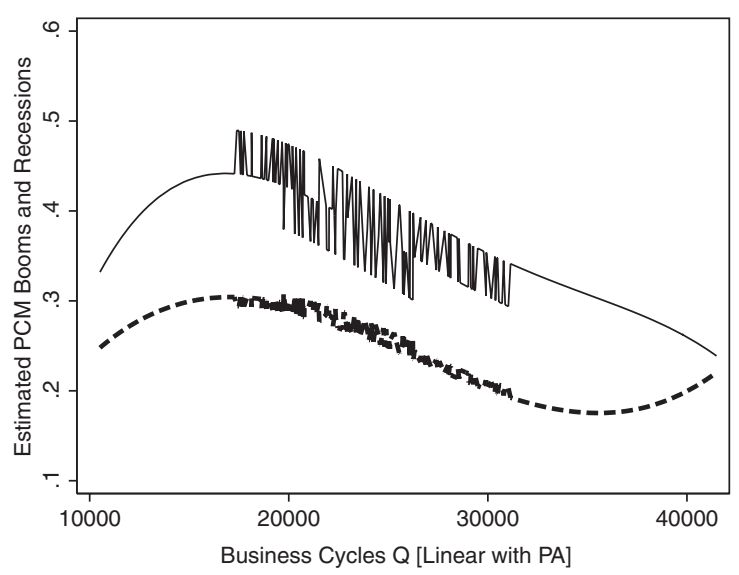

the volume of trade and the grain rate for the cartel can both increase. Given that the JEC had higher monopolistic power during the lakes closed regime, it is interesting to see profits peaking at the end of the lakes open periods. This highlights the role of, and the need to have, data on the actual external demand cycles that come from inventory management

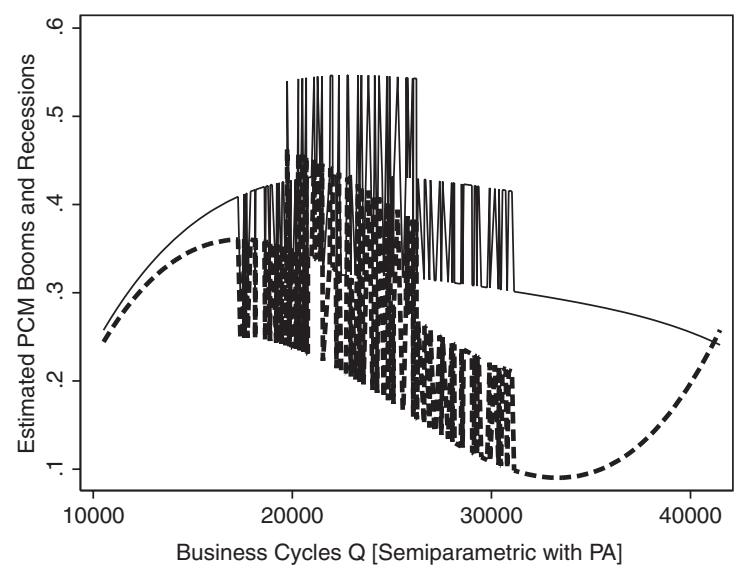

in New York, which attempts to mitigate the potential high costs of transportation created by the lakes closing. The use of inventories over the seasons creates interesting deterministic demand and pricing cycles. The end of the lakes open period is now the expected boom period for the JEC. This is at first sight surprising given that their competitors on the lakes and 
TABLE 7.-POSTREgRESSION ESTIMATION OF PCM DURING BOOM AND RECESSION

\begin{tabular}{|c|c|c|c|c|c|}
\hline \multirow[b]{3}{*}{ Phase } & \multirow[b]{3}{*}{ Variables } & \multicolumn{4}{|c|}{ PCM Business Cycle } \\
\hline & & \multicolumn{2}{|c|}{ Baseline Model } & \multicolumn{2}{|c|}{ Partial Adjustment Model } \\
\hline & & $\begin{array}{c}1 \\
\text { Linear } 2 \text { SLS }\end{array}$ & $\frac{2}{\text { Semiparametric } 2 \text { SLS }}$ & $\begin{array}{c}3 \\
\text { Linear 2SLS }\end{array}$ & $\begin{array}{c}4 \\
\text { Semiparametric 2SLS }\end{array}$ \\
\hline \multirow[t]{9}{*}{ Boom } & & & & & \\
\hline & Cons & $\begin{array}{c}-1.027^{* *} \\
(0.436)\end{array}$ & $\begin{array}{c}-0.013 \\
(0.318)\end{array}$ & $\begin{array}{c}-1.035^{* *} \\
(0.419)\end{array}$ & $\begin{array}{c}-0.134 \\
(0.334)\end{array}$ \\
\hline & $\mathrm{N}$ & $\begin{array}{l}0.056^{* * *} \\
(0.011)\end{array}$ & $\begin{array}{l}-0.106^{* * *} \\
(0.008)\end{array}$ & $\begin{array}{l}0.048^{* * *} \\
(0.010)\end{array}$ & $\begin{array}{l}-0.113^{* * *} \\
(0.008)\end{array}$ \\
\hline & $\frac{\tilde{Q}}{10000}$ & $\begin{array}{l}2.073^{* *} \\
(0.804)\end{array}$ & $\begin{array}{l}1.173^{* *} \\
(0.586)\end{array}$ & $\begin{array}{l}2.067^{* * *} \\
(0.773)\end{array}$ & $\begin{array}{l}1.354^{* *} \\
(0.616)\end{array}$ \\
\hline & $\left(\frac{\tilde{Q}}{10000}\right)^{2}$ & $\begin{array}{c}-1.160^{* *} \\
(0.519)\end{array}$ & $\begin{array}{c}-0.553 \\
(0.378)\end{array}$ & $\begin{array}{c}-1.160^{* *} \\
(0.498)\end{array}$ & $\begin{array}{r}-0.659^{*} \\
(0.397)\end{array}$ \\
\hline & $\left(\frac{\tilde{Q}}{10000}\right)^{3}$ & $\begin{array}{r}0.264^{*} \\
(0.141)\end{array}$ & $\begin{array}{c}0.113 \\
(0.103)\end{array}$ & $\begin{array}{r}0.266^{*} \\
(0.136)\end{array}$ & $\begin{array}{c}0.141 \\
(0.108)\end{array}$ \\
\hline & $\left(\frac{\tilde{Q}}{10000}\right)^{4}$ & $\begin{array}{r}-0.022 \\
(0.014)\end{array}$ & $\begin{array}{c}0.009 \\
(0.010)\end{array}$ & $\begin{array}{r}-0.022^{*} \\
(0.013)\end{array}$ & $\begin{array}{c}-0.011 \\
(0.011)\end{array}$ \\
\hline & Observations & 135 & 135 & 135 & 135 \\
\hline & Adjusted $R^{2}$ & 0.497 & 0.751 & 0.474 & 0.739 \\
\hline \multirow[t]{7}{*}{ Recession } & Cons & $\begin{array}{r}-0.131 \\
(0.166)\end{array}$ & $\begin{array}{r}-0.091 \\
(0212)\end{array}$ & $\begin{array}{r}-0.153 \\
(0.156)\end{array}$ & $\begin{array}{r}-0.184 \\
(0.221)\end{array}$ \\
\hline & $\mathrm{N}$ & $\begin{array}{r}-0.010 \\
(0.010)\end{array}$ & $\begin{array}{l}-0.107^{* * *} \\
(0.013)\end{array}$ & $\begin{array}{r}-0.010 \\
(0.010)\end{array}$ & $\begin{array}{l}-0.112^{* * *} \\
(0.014)\end{array}$ \\
\hline & $\frac{\tilde{Q}}{10000}$ & $\begin{array}{l}0.704^{* * *} \\
(0.214)\end{array}$ & $\begin{array}{l}1.280^{* * *} \\
(0.273)\end{array}$ & $\begin{array}{l}0.693^{* * *} \\
(0.200)\end{array}$ & $\begin{array}{l}1.380^{* * *} \\
(0.284)\end{array}$ \\
\hline & $\left(\frac{\tilde{Q}}{10000}\right)^{2}$ & $\begin{array}{c}-0.305^{* * *} \\
(0.090)\end{array}$ & $\begin{array}{l}-0.561^{* * *} \\
(0.115)\end{array}$ & $\begin{array}{c}-0.300^{* * *} \\
(0.084)\end{array}$ & $\begin{array}{l}-0.601^{* * *} \\
(0.119)\end{array}$ \\
\hline & $\left(\frac{\tilde{Q}}{10000}\right)^{3}$ & $\begin{array}{l}0.039^{* * *} \\
(0.018)\end{array}$ & $\begin{array}{l}0.074^{* * *} \\
(0.002)\end{array}$ & $\begin{array}{l}0.038^{* * *} \\
(0.011)\end{array}$ & $\begin{array}{l}0.079^{* * *} \\
(0.016)\end{array}$ \\
\hline & Observations & 116 & 116 & 116 & 116 \\
\hline & Adjusted $R^{2}$ & 0.274 & 0.549 & 0.280 & 0.536 \\
\hline
\end{tabular}

canals are open for business. One must realize, however, that inventories offer even more aggressive competitive pressures when the lakes are closed.

\section{Step 3: Cyclical Nature of Markups}

Having estimated the component of pricing that reflects a markup over marginal cost, we can now analyze some of its behavioral patterns. In particular, we provide evidence of strategic pricing by a legal cartel over the deterministic demand cycles that were created by inventory management, as necessitated by the seasonal opening and closing of transportation over the Great Lakes. We represent the smoothed price-cost margin and profit cycles against rescaled output cycles in figure 6. Can we see obvious counter cyclical or procyclical movements of markups with output? What emerges is that during periods of cartel stability, we observe four lakes reopen episodes where output and price-cost margins move up together as we move toward lakes closing. This generates rising profits that peak just before the lakes close. We also see that during periods of cartel stability, we have five lakes closed episodes, where output is rising but price-cost margins are falling, as we move closer to lakes opening. Periods of instability are less clear-cut but look countercyclical. To test the theory of Haltiwanger and Harrington during the collusive periods, we regress price-cost margins during upswings and price-cost margins during downturns on the number of firms and on a polynomial function of the demand business cycle. The results from the regression are reported in table 7 and plotted in figure 7.18 The Haltiwanger and Harrington theory seems to be validated: for the same level of grain demanded, the price (markup) is lower when the JEC is in a period of prolonged decline in demand, compared to coming into a period of prolonged increase in demand. This gap is narrowed when the JEC expands the number of firms in the cartel, which is again consistent with the theory. Higher markups coming in to an expected prolonged increase in demand are harder to sustain when the JEC has more members. This is powerful evidence that during periods of stability, the JEC did price optimally over deterministic demand cycles, creating interesting dynamics in markups that reiterate those found in Borenstein and Shepard (1996). This is strong evidence that pricing in cartels reacts in a predictable way to anticipated demand cycles. It is not just the current level of demand that matters but the expectation of a continued expansion in demand that leads to sustainable high price-cost margins.

\footnotetext{
18 The spikes in the figures are due to the number of firms varying from three to five during the period. We have no spikes when there are four firms, decreasing spikes when we have five firms, and increasing spikes in case of three firms.
} 


\section{Conclusion}

The use of commodity prices in Chicago and New York, spot and future, through finance theory allows us to construct the expected transportation rates across the dominant modes of transportation between Chicago and New York. We also construct the expected marginal net convenience yield of holding inventories in New York. Finally, we measure the unexpected demand shocks in New York commodity markets that lead to realized mistakes in pricing and volume (expectations of prices and inventories) setting by transportation modalities. These variables are estimated to have a tremendous impact on the modeling of equilibrium price-cost margin movements in the JEC.

In terms of modeling the linear marginal cost component of pricing, our model of output is greatly enhanced with the addition of our new data. The market elasticity of demand is now made up of an important cross-price, as well as an own-price, effect. We also include year dummies, controls for spikes in demand by elevators in New York and partial adjustment effects. This model of demand allows us to instrument and model marginal cost, and hence pricing, relatively better.

In terms of modeling the second component of pricing, the markup, we model it as a function of deterministic demand cycles and condition it on expected cartel stability one period ahead. Cartel instability is found to be triggered by realized errors in forecasts of commodity price shocks in New York rather than demand cycles. An unanticipated boom in New York can make the cartel unstable, as firms with imperfect monitoring of other firms realize that price and output should have been higher last period leading to finite periods of breakdown, as suggested in Green and Porter (1984). In stable periods, the markup is modeled to depend on anticipated demand cycles. Due to the short window of opportunity between harvesting and lakes closing, inventory management over the Great Lakes and canals leads to distinctive deterministic demand cycles for the railroad cartel to set prices against. We estimate the equilibrium price path semiparametrically (linear marginal cost and the nonlinear markup function) simultaneously to the demand. Linear estimates of the parameters of marginal cost allow us to backout the nonparametric function to estimate rich weekly markup and profit cycles. We test for optimal collusive pricing over the deterministic cycles and find, for the same volume of sales, that the markup in a prolonged boom tends to be higher when compared to the markup coming into a prolonged recession. In other words, the JEC set prices over deterministic demand cycles in a way that supports the theoretical considerations in Haltiwanger and Harrington (1991). As highlighted in Borenstein and Shepard (1996), such cyclical pricing may be a way of detecting illegal pricing behavior in a modern cartel.

\section{REFERENCES}

Aldrich Report, U.S. 52nd Congress 2nd Session, Senate Report 1394. Wholesale Prices, Wages and Transportation Report by Mr. Aldrich from the Committee on Finance. Part 1 (Washington, DC: Government Printing Office, 1893).

Appelbaum, E., "The Estimation of the Degree of Oligopoly Power," Journal of Econometrics 19 (1982), 287-299.

Berry, S., J. Levinsohn, and A. Pakes, "Automobile Prices in Market Equilibrium,” Econometrica 63 (1995), 841-890.

Borenstein, S., and A. Shepard, "Dynamic Pricing in Retail Gasoline Markets," Rand Journal of Economics 27 (1996), 429451.

Bresnahan, T., "Empirical Studies of Industries with Market Power" (pp. 1011-1058), in Richard Schmalensee and Robert Willig (eds.), Handbook of Industrial Organization (Amsterdam: North-Holland, 1989).

Coleman, A., "Storage, Slow Transport and the Law of One Price: Theory with Evidence from Nineteenth Century U.S. Corn Markets," this REVIEW, 91 (2009), 332-350.

Ellison, G., "Theories of Cartel Stability and the Joint Executive Committee," Rand Journal of Economics 25 (1994), 37-57.

Fabra, N., "Collusion with Capacity Constraints over the Business Cycle," International Journal of Industrial Organization 24 (2006), 69-81.

Gallet C. A., and J. R., Schroeter, "The Effects of the Business Cycle on Oligopoly Coordination: Evidence from the U.S. Rayon Industry," Review of Industrial Organization 10 (1995), 181-196.

Genesove, D., and W. Mullin, "Testing Static Oligopoly Models: Conduct and Cost in the Sugar Industry, 1890-1914," Rand Journal of Economics 9 (1998), 355-377.

Green, E., and R. Porter, "Noncooperative Collusion under Imperfect Price Information," Econometrica 52 (1984), 87-100.

Haltiwanger, J., and J. Harrington, "The Impact of Cyclical Demand Movement on Collusive Behavior," Rand Journal of Economics 22 (1991), 89-106.

Hodrick, R., and E. Prescott, "Post-War U.S. Business Cycles: An Empirical Investigation," Journal of Money, Credit and Banking 29 (1997), $1-16$.

Holmes, T. J., "The Effects of Third-Degree Price Discrimination in Oligopoly," American Economic Review 79 (1989), 244 250 .

Lee, L. F., and R. H. Porter, "Switching Regression Models with Imperfect Sample Separation Information: With an Application on Cartel Stability," Econometrica 52 (1984), 391-418.

Mariuzzo, F., P. P. Walsh, and C. Whelan, "Coverage of Retail Stores and Discrete Choice Models of Demand: Estimating Price Elasticities and Welfare Effects," International Journal of Industrial Organization 28 (2010), 555-578.

Pindyck, R. S., "Inventories and the Short-Run Dynamics of Commodity Prices," Rand Journal of Economics 25 (1994), 141-159.

Porter, R., "A Study of Cartel Stability: The Joint Executive Committee, 1880-1886," Bell Journal of Economics 14 (1983), 301314.

"On the Incidence and Duration of Price Wars," Journal of Industrial Economics 33 (1985), 415-426.

Robinson, P. M., "Root-N-Consistent Semiparametric Regression," Econometrica 56 (1988), 931-954.

Rotemberg, J., and G. Saloner, "A Supergame Theoretic Model of Price Wars during Booms," American Economic Review 76 (1986), 390 407.

Thurman, W. N., "Speculative Carryover: An Empirical Examination of the U.S. Refined Copper Market," Rand Journal of Economics 19 (1988), 420-437.

Ulen, T. S., "Cartels and Regulation: Late Nineteenth Century Railroad Collusion and the Creation of the Interstate Commerce Commission," PhD dissertation, Stanford University (1979).

"Railroad Cartels before 1887: The Effectiveness of Private Enforcement of Collusion," Research in Economic History 8 (1983), 125-144.

Vasconcelos, H., "Entry Effects on Cartel Stability and the Joint Executive Committee," Review of Industrial Organization 24 (2004), 219_ 241.

Walters, A. A., "Production and Cost Functions: An Econometric Survey," Econometrica 31 (1967), 1-66.

Working, H., "The Theory of Price of Storage," American Economic Review 39 (1949), 1254-1262. 